\title{
Safe and easy evaluation of tmRNA-SmpB-mediated trans-translation in ESKAPE pathogenic bacteria
}

Marion Thépaut ${ }^{1,2}$, Rodrigo Campos Da Silva ${ }^{1,3}$, Eva Renard $^{4}$, Frédérique Barloy-Hubler ${ }^{1}$, Eric Ennifar ${ }^{4}$, Daniel Boujard ${ }^{1}$, and Reynald Gillet ${ }^{1 *}$

${ }^{1}$ Univ. Rennes, CNRS, Institut de Génétique et Développement de Rennes (IGDR) UMR 6290, Rennes, France

${ }^{2}$ SATT Ouest-Valorisation, Rennes, France

3 Programa de Pós-Graduação em Ciências Farmacêuticas, Faculdade de Farmácia, Universidade Federal do Rio Grande do Sul, Porto Alegre, Brazil

${ }^{4}$ Architecture et Réactivité de l'ARN - CNRS UPR 9002, Institut de Biologie Moléculaire et Cellulaire, Université de Strasbourg, Strasbourg, France

* Corresponding author: Reynald Gillet

E-mail: reynald.gillet@univ-rennes1.fr

Running title: Evaluation of trans-translation in ESKAPE bacteria

Keywords: Trans-translation, tmRNA, ESKAPE, antibiotics, HTS, resistance

\section{Abstract}

Bacteria cope with ribosome stalling thanks to trans-translation, a major quality control system of protein synthesis that is mediated by tmRNA, an hybrid RNA with properties of both a tRNA and an mRNA, and the small protein SmpB. Because trans-translation is absent in eukaryotes but necessary for bacterial fitness or survival, it is a promising target for the development of novel antibiotics. To facilitate screening of chemical libraries, various reliable in vitro and in vivo systems have been created for assessing trans-translational activity. However, none of these permits the safe and easy evaluation of trans-translation in pathogenic bacteria, which are obviously the ones we should be targeting. Based on green fluorescent protein (GFP) reassembly during active trans-translation, we have created a cell-free assay adapted to the rapid evaluation of trans-translation in ESKAPE bacteria, with 24 different possible combinations. It can be used for easy high-throughput screening of chemical compounds as well as for exploring the mechanism of trans-translation in these pathogens. 
JBC "Methods and Resources" submission. Thépaut et al., Evaluation of trans-translation in ESKAPE bacteria

\section{Introduction}

The World Health Organization (WHO) designated six 'ESKAPE' pathogens (Enterococcus faecium, Staphylococcus aureus, Klebsiella pneumoniae, Acinetobacter baumannii, Pseudomonas aeruginosa, and Enterobacter spp.) as critical targets for drug discovery (Rice et al., 2008; Tacconelli and Magrini, 2017). Indeed, these bacteria are the leading cause of nosocomial infections throughout the world, and most are multidrug-resistant isolates (Santajit and Indrawattana, 2016). The WHO recommendation is to focus specifically on the discovery and development of new antibiotics that are active against multidrug- and extensively drugresistant ESKAPE bacteria. However, the hazardous nature of these pathogens makes it highly challenging to develop high-throughput screening methods for identifying and evaluating any new antimicrobial agents for future clinical use. To aid in this, the molecular process to be targeted must first be identified, and ideally this process should be: i) conserved among all pathogenic ESKAPE bacteria; ii) indispensable to bacterial survival or at least its fitness; iii) sufficiently variable that different species can be distinguished from each other; iv) absent in eukaryotes; v) not targeted by current antibiotics; vi) unrelated to existing resistance mechanisms; and finally vii) reproducible in non-hazardous in vitro experiments.

In fact, trans-translation appears to be the perfect candidate. This mechanism is the primary bacterial rescue system, allowing for the release of ribosomes stalled on faulty mRNAs that lack stop codons as well as the elimination of these mRNAs and mistranslated peptides. The trans-translation process is performed by hybrid transfer-messenger RNA (tmRNA) and its protein partner SmpB (Giudice et al., 2014). Briefly, the tmRNA-SmpB complex recognizes the stalled ribosome and associates with it. In a finely orchestrated ballet, translation then resumes on tmRNA's internal mRNA-like domain (MLD), which encodes a specific sequence that is recognized by proteases. This process permits the stalled ribosomes to be recycled, the degradation of the incomplete peptide after its release, and elimination of the problematic nonstop mRNA. Remarkably, genes coding for tmRNA and SmpB have been found in nearly all bacterial genomes, yet not in eukaryotes, with the exception of a very few rare organelles (Hudson and Williams, 2015). Despite high sequence conservation at both the 5'- and 3'-ends of tmRNA genes, the internal sequences of tmRNA are considerably divergent among different species (Supp. Fig. 1), and this property makes tmRNA a good tool for species identification (Schonhuber et al., 2001). In the same way, despite global structural conservation, variations in $s m p B$ sequences are also considerably divergent among different species (Supp. Fig. 1). 
While resolving stalled ribosomal complexes is undoubtedly a matter of life or death (Keiler and Feaga, 2014), trans-translation itself is not always indispensable to bacterial survival. This irregularity was the subject of a long debate until the discovery of backup systems, mechanisms which take over if trans-translation is deficient or overwhelmed. However, even when they are present, these systems are not enough to ensure a steady and prolonged fitness to the cell, as impaired trans-translation is known to result in various phenotypes varying from mild (such as loss of tolerance to multiple antibiotics and stresses) to severe (including lethality or loss of virulence) (Li et al., 2013; Keiler and Feaga, 2014). To date, trans-translation has not been yet exploited for clinical use. In the search for inhibitors specific to the process, initial assays led to the discovery of 1,3,4 oxadiazole molecules (Ramadoss et al., 2013), but their activity in vivo is still in question (Macé et al., 2017; Brunel et al., 2018). It has been suggested that trans-translation is inhibited by pyrazinamide (PZA), a first-line anti-tuberculosis drug (Shi et al., 2011), but it was finally recently shown the action of PZA is entirely independent of trans-translation in M. tuberculosis (Dillon et al., 2017).

Because of its biological properties, transposition of trans-translation into a nonhazardous system that could allow for rapid and easy evaluation of its activity would greatly help in the search for new antibiotics which target this system. While there are routine methods for screening the antimicrobial activity of compounds from chemical libraries, a combination of this primary screening with the specification of a molecular target is much harder to implement (Osterman et al., 2016). An ideal method would allow not just the identification of the targeted cellular process, but also its level of specificity toward a bacterial genus or species. Furthermore, an easy quantitative and rapid analysis of the process should be possible even in small volumes. Reporter assays are the best candidates for efficient initial high-throughput screening (HTS) methods, as they can be quick and automated, as well as quite useful for screening unpurified mixtures of natural extracts (Osterman et al., 2016). Accordingly, we recently used a commercial reconstituted in vitro translation system (PURExpress) to create a reliable in vitro reporter system that detects the $E$. coli trans-translation activity (Guyomar et al., 2020). This assay, based on reassembling an active "superfolder" Green Fluorescent Protein (sfGFP) after tmRNA tagging (Fig. 1), was designed and validated for the specific in vitro quantification of trans-translation in ESKAPE pathogenic bacteria, and we report on that here. 
A

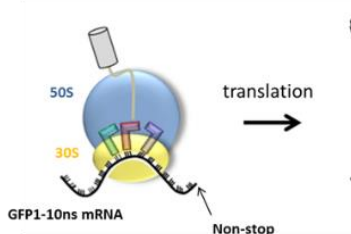

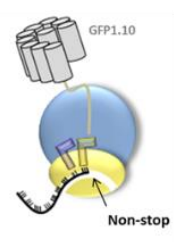

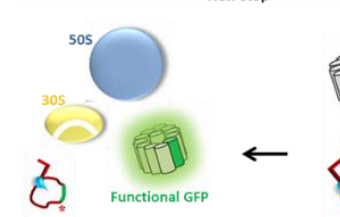

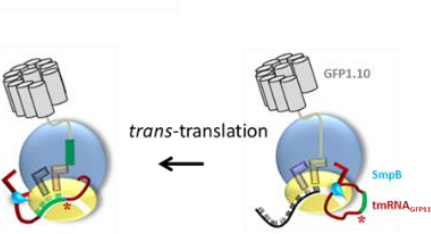

B

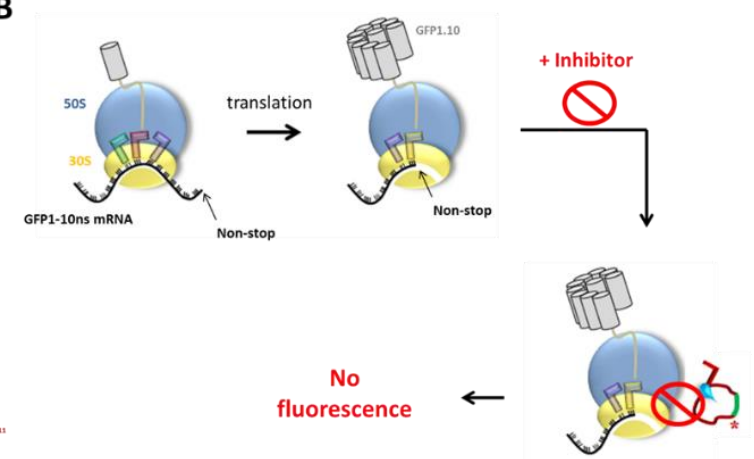

Figure 1. A. Trans-translation of sfGFP1-10 mRNA lacking a stop codon. The tmRNA $\mathrm{GFP}_{11}-\mathrm{SmpB}$ complex binds to the stalled ribosome, and translation resumes thanks to the tmRNAGFP11 mRNA-like domain (MLD). The MLD encodes the missing eleventh domain of the sfGFP, and the complete sfGFP is released and becomes fluorescent. B. Impairment of the process in the presence of transtranslation inhibitors. The ribosomes stay stalled on the problematic mRNA and fluorescence is impaired.

\section{Results}

\section{Distribution of ArfA and ArfB in ESKAPE bacterial genomes}

If some bacteria can live without trans-translation, this is only because they have at least one of the two alternative release factors, ArfA and ArfB (Himeno et al., 2015). Indeed, the ArfA or ArfB backup systems are essential if trans-translation is aborted. Depending on backup system status, therefore, the effects of specific inhibitors of trans-translation will vary - from increasing the activity of currently used antibiotics to outright cell death. It was therefore important for us to begin by pinpointing the phylogenetic distribution of ArfA and ArfB in ESKAPE pathogens. To do this, we investigated the sequences of those rescue factors using a combination of in silico methods including keyword searches, similarity detection, protein domain prediction, ortholog clustering, and synteny analysis. This pipeline was applied to the complete genomic sequences of 1,670 species: 148 E. faecium, 459 S. aureus, $465 \mathrm{~K}$. pneumoniae, 188 A. baumannii, 259 P. aeruginosa, and 151 Enterobacter spp. Interestingly, among these ESKAPE pathogens, neither of the two back-up systems were found in $A$. baumannii or the two Gram-positive bacteria E. faecium and S. aureus (Table 1). While we cannot categorically state that no backup systems exist in these bacteria - see for instance the 
JBC "Methods and Resources" submission. Thépaut et al., Evaluation of trans-translation in ESKAPE bacteria

recent reports on ArfT in Francisella tularensis and BrfA in Bacillus subtilis (Goralski et al., 2018; Shimokawa-Chiba et al., 2019) - we can however suppose that their viability depends on trans-translation impairment. On the other hand, we found genes encoding ArfA and/or ArfB in most if not all of the K. pneumonia, P. aeruginosa, and Enterobacter spp. studied. The impairment of trans-translation in these bacteria is probably less severe, therefore, even if it still detrimental to bacterial fitness.

Table 1. Distribution of ArfA and ArfB in ESKAPE bacteria

\begin{tabular}{|l|c|c|c|}
\hline ESKAPE pathogen & \# of screened genomes & arfA & arfB \\
\hline Enterococcus faecium & 148 & 0 & 0 \\
\hline Staphylococcus aureus & 459 & 0 & 0 \\
\hline Klebsiella pneumoniae & 465 & $464+1 \Delta$ & $459+6 \Delta$ \\
\hline Acinetobacter baumannii & 188 & 0 & 0 \\
\hline Pseudomonas aeruginosa & 259 & 259 & 259 \\
\hline Enterobacter spp. & 151 & 151 & $150+3 \Delta$ \\
\hline
\end{tabular}

$\Delta$ pseudogenes with frameshift or « in-frame » stop codon.

\section{ESKAPE tmRNA and SmpB production}

To allow for independent monitoring of trans-translation in these six ESKAPE pathogens, we engineered their tmRNAs by replacing their internal MLD with a sequence of 16 amino acids that encodes GFP's eleventh domain (Supp. Table 1). To conserve the tmRNA H5 helix that is instrumental during trans-translation, we also engineered compensatory mutations (Guyomar et al., 2020, and Fig. 2A, B). Unlike those of the other bacteria, the natural tmRNA 3 '-ends in E. faecium and S. aureus are not CCA but UUG and UAU, respectively, so these were replaced by CCA to ensure correct aminoacylation by E. coli AlaRS (Barends et al., 2000), and these variants were named tmRNA $\mathrm{GFP11}_{\text {. }}$ 
A

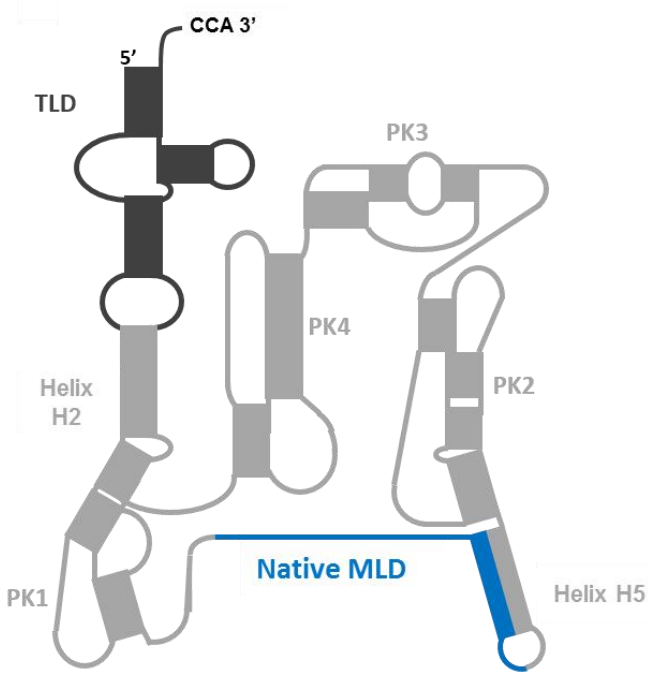

\section{C}

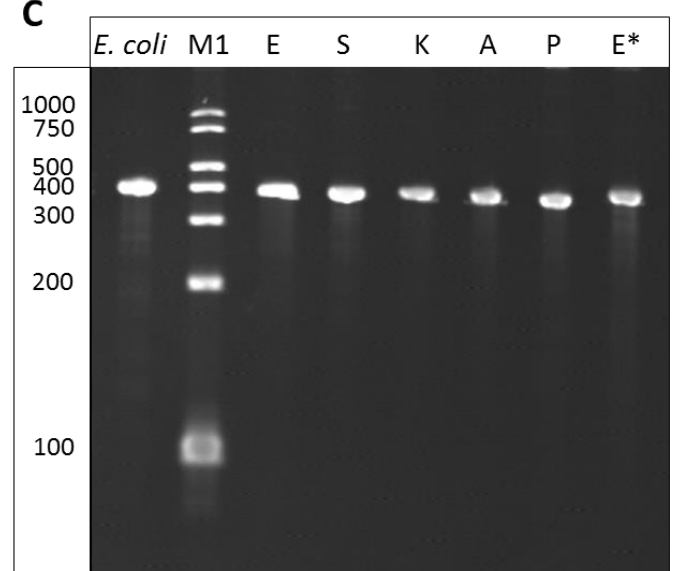

B
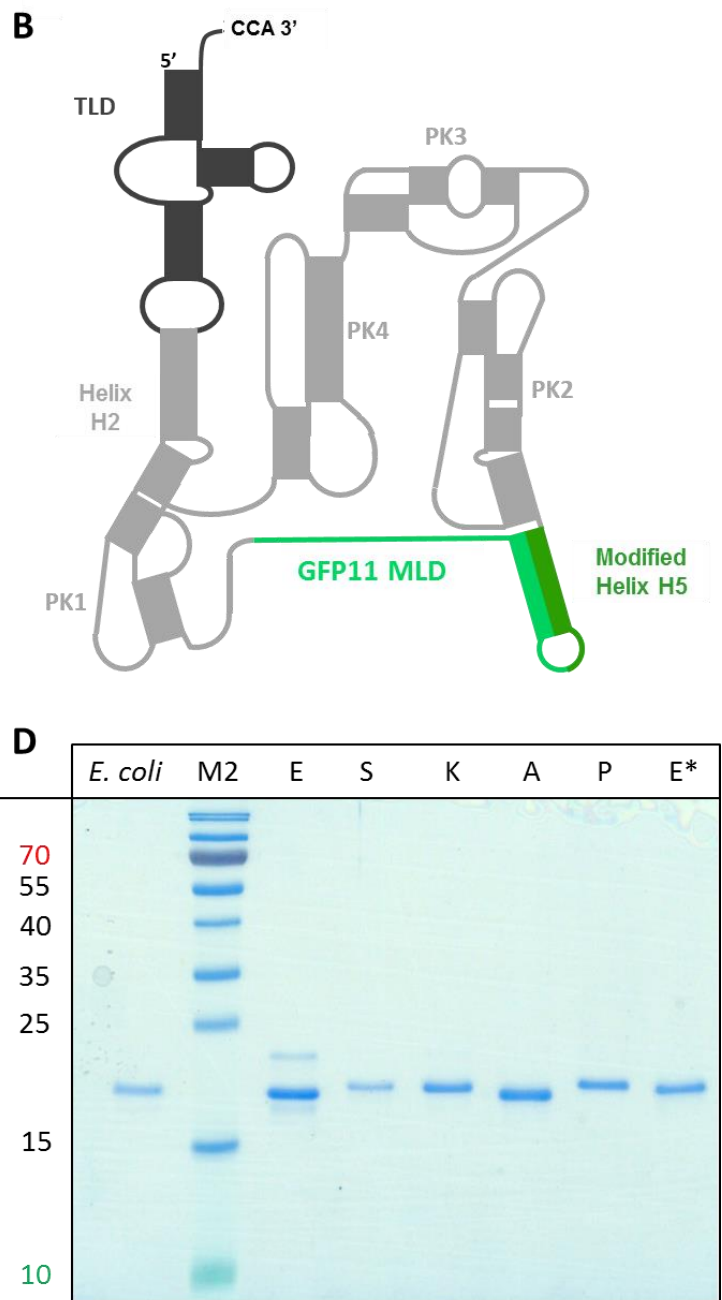

Figure 2. Schematic illustrations of tmRNA secondary structures as well as production patterns of tmRNA and SmpB variants. (A) Wild-type tmRNA, with a black transfer-like domain (TLD) and blue messenger-like domain (MLD). (B) Mutated tmRNA ${ }_{\mathrm{GFP} 11}$ has an engineered MLD (light green) that encodes the eleventh GFP domain beta-strand. Compensatory mutations (dark green) maintain the base-pairing interactions of the $\mathrm{H} 5$ helix, and the $3^{\prime}$-ends for all species are CCA (Adapted from Guyomar et al., 2020.) (C) Visualization of ESKAPE tmRNA ${ }_{\mathrm{GPP} 11}$ variants (5 pmol) on $8 \%$ urea-PAGE, with $E$. coli tmRNA GFP11 $_{1}$ used as a control. (D) As C, but showing 50 pmol E. coli and ESKAPE SmpB on 15\% SDS-PAGE. Key: M1, RNA Century ${ }^{\mathrm{TM}}$-Plus Markers (ThermoFisher Scientific), M2, PageRuler ${ }^{\mathrm{TM}}$ Prestained Protein Ladder, 10 to $180 \mathrm{kDa}$ (ThermoFisher Scientific), E, Enterococcus faecium; S, Staphylococcus aureus; K, Klebsiella pneumoniae; A, Acinetobacter baumannii; P, Pseudomonas aeruginosa; $\mathrm{E}^{*}$, Enterobacter cloacae.

Urea-PAGE analysis indicated that the six tmRNA variants were successfully produced at the expected size, without any noticeable degradation or unexpected bands (Fig. 2C). We started with $10 \mu \mathrm{g}$ plasmidic DNA, and the final yields were about $4 \mathrm{nmol}$ of transcribed RNAs for each reaction. The six corresponding $\mathrm{SmpB}$ proteins were cloned and produced in vivo in $E$. coli (see Experimental Procedures). After purification, acrylamide analysis confirmed the 
JBC “Methods and Resources" submission. Thépaut et al., Evaluation of trans-translation in ESKAPE bacteria

correct size of each protein (Fig. 2D). The final yields for each ESKAPE SmpB were about half the amount of the E. coli SmpB produced.

\section{ESKAPE trans-translation reactions}

In order to obtain non-productive translation complexes (NTCs) to be targeted by transtranslation, we used a reconstituted cell-free protein synthesis (NEB PURExpress) system from E. coli (Shimizu, et al., 2001, Shimizu and Ueda, 2002). By adding a non-stop DNA template, we were able to accumulate stalled ribosomes with the ten first domains of sfGFP stuck in the ribosome exit tunnel (Fig. 1A). When tmRNA ${ }_{\mathrm{GFP} 11}$ and E. coli SmpB are added, the ribosomes are freed and the intensity of the fluorescent signal increases over time while the complete sfGFP protein is produced. A plateau is reached at $\sim 4$ hours of incubation, and the fluorescence remains stable for at least 710 minutes (Fig. 3A, black curve).

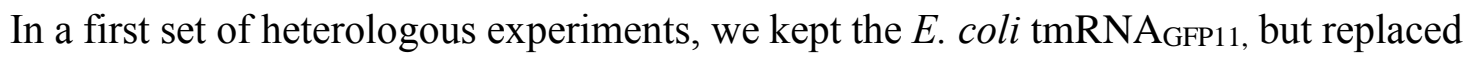
its SmpB by one from an ESKAPE pathogen. A fluorescent signal was still recovered with each one of the hetero-complexes, albeit at different levels (Fig. 3A). The E. cloacae, S. aureus, and P. aeruginosa SmpBs displayed the lowest signals, less than $30 \%$ of the E. coli control, while the K. pneumoniae SmpB signal was about half the control, and E. faecium and A. baumannii at $80 \%$. This demonstrates that all of the ESKAPE SmpBs are functional and sufficiently conserved to be interchangeable in the presence of E. coli tmRNA. While it confirms that SmpB is highly conserved (Supp. Fig. 1), it also supports the use of this simple system for screening molecules that target SmpB but not tmRNA. Indeed, since SmpB is essential for tmRNA's peptide-tagging activity (Karzai et al., 1999), disrupting SmpB is one of the most promising ways to impair trans-translation. In fact, aptamers that inhibit SmpB functioning were recently shown to trigger strong growth defects in Aeromonas veronii C4 (Liu et al., 2016).

We then performed the experiments the other way around, using the E. coli SmpB but the tmRNAs from the ESKAPE pathogens. Contrary to the previous experiments, only the 
JBC "Methods and Resources" submission. Thépaut et al., Evaluation of trans-translation in ESKAPE bacteria

183

184

185

186

187

188

189

190

191

192

193

194

195

heteroduplexes combining E. coli SmpB and the tmRNAs from K. pneumoniae and E. cloacae gave out strong signals, about the same levels as those recovered in the E. coli tmRNA control (Fig. 3B). This is not a surprise since, like E. coli, both K. pneumoniae and E. cloacae are Enterobacteriaceae with very similar tmRNA sequences ( $\geq 95 \%$ identity with $E$. coli, see Supp.

Fig. 1). The four other bacterial species all produced signals, but at lower levels (about 5 to $20 \%$ of the reference).

We continued by performing homologous experiments, using $\mathrm{SmpB}$ and tmRNA $\mathrm{GFP}_{11}$ from the same ESKAPE pathogen, but this time with E. coli ribosomes (Fig. 3C). Five of the six complexes yielded positive results. Three of these were at high levels ( $\sim 50 \%$ compared to the E. coli reference): K. pneumonia; E. cloacae and E. faecium. The other two were at lower levels (about $5-10 \%$ of the reference): A. baumannii, another Gammaproteobacteria that is relatively close to Enterobacteriaceae; and the Gram-positive $S$. aureus. The Gammaproteobacteria $P$. aeruginosa did not work at all. 
bioRxiv preprint doi: https://doi.org/10.1101/2020.12.16.423090; this version posted December 17, 2020. The copyright holder for this preprint (which was not certified by peer review) is the author/funder. All rights reserved. No reuse allowed without permission.

JBC "Methods and Resources" submission. Thépaut et al., Evaluation of trans-translation in ESKAPE bacteria
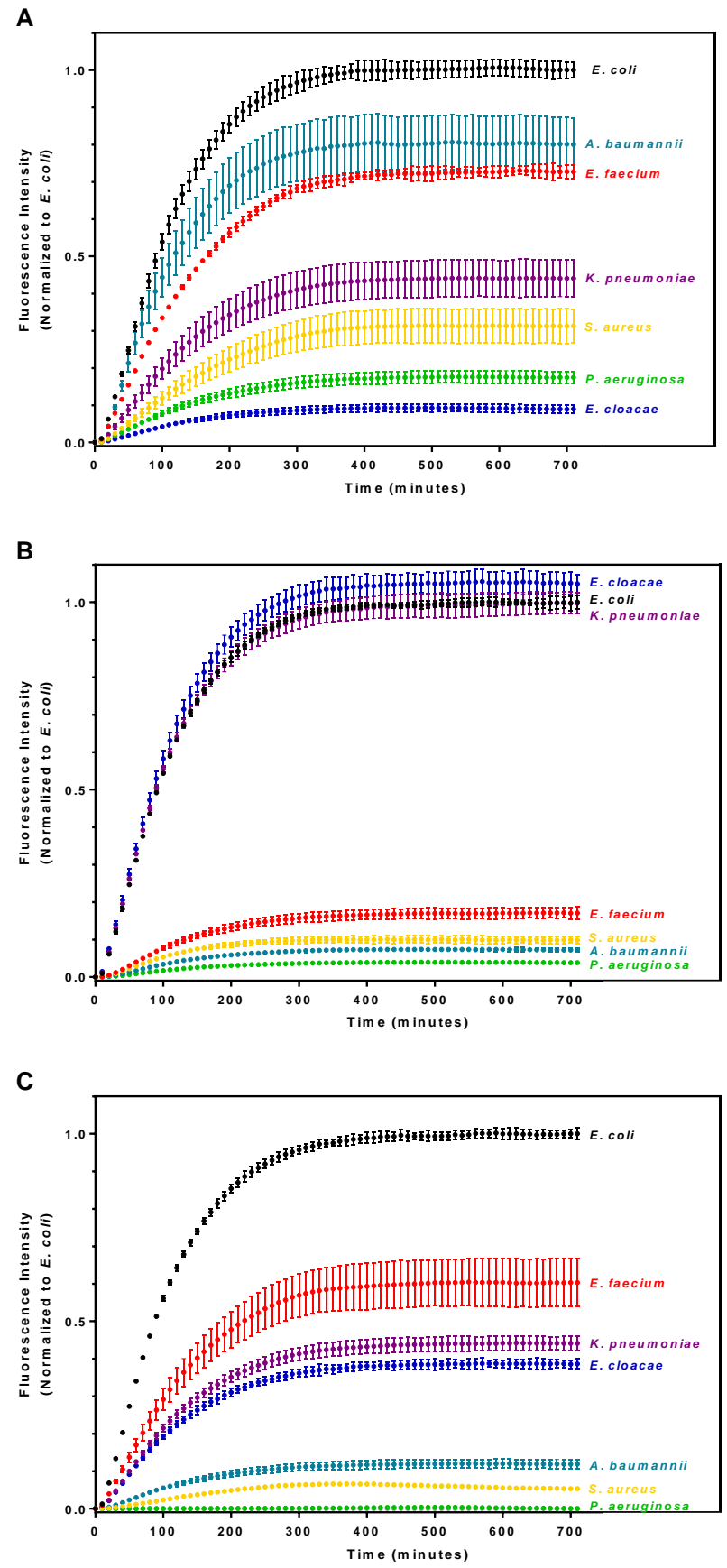

Figure 3: Trans-translation kinetics over time using Escherichia coli ribosomes. Fluorescence increases are directly linked to trans-translation activity. A) Trans-translation assays were done on $E$. coli tmRNA ${ }_{\mathrm{GFP} 11}$ using the SmpBs from each ESKAPE pathogen, with the E. coli SmpB as a control.

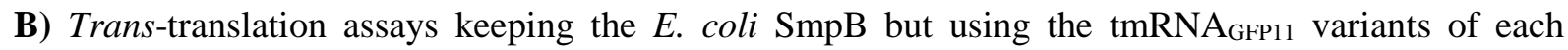
ESKAPE pathogen, with an E. coli tmRNA $_{\mathrm{GFP} 11}$ as the control. C) Both SmpB and tmRNA $\mathrm{GFP}_{11}$ are from each ESKAPE pathogen, with the E. coli SmpB-tmRNA ${ }_{\mathrm{GFP} 11}$ as a control. The results are shown as means \pm standard deviation and normalized to the E. coli conditions. 
JBC "Methods and Resources" submission. Thépaut et al., Evaluation of trans-translation in ESKAPE bacteria

In a final set of experiments, we used homologous tmRNA-SmpB complexes in the presence of their corresponding ESKAPE ribosomes. The use of the PURExpress $\Delta$ Ribosome

A

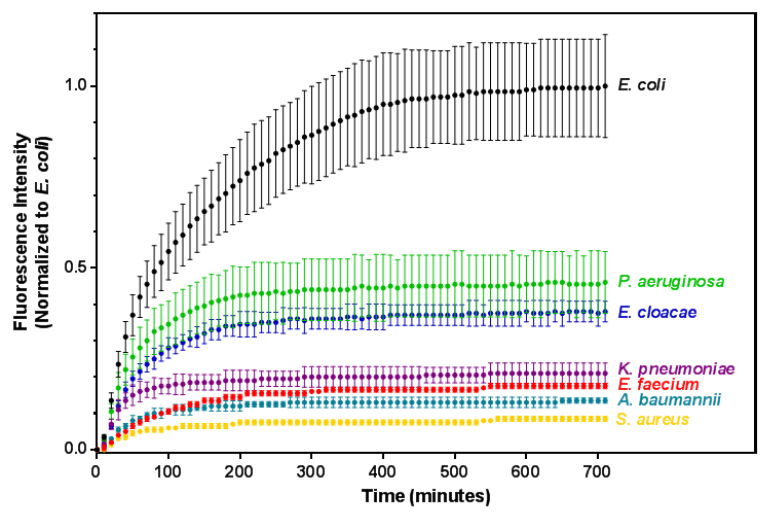

B

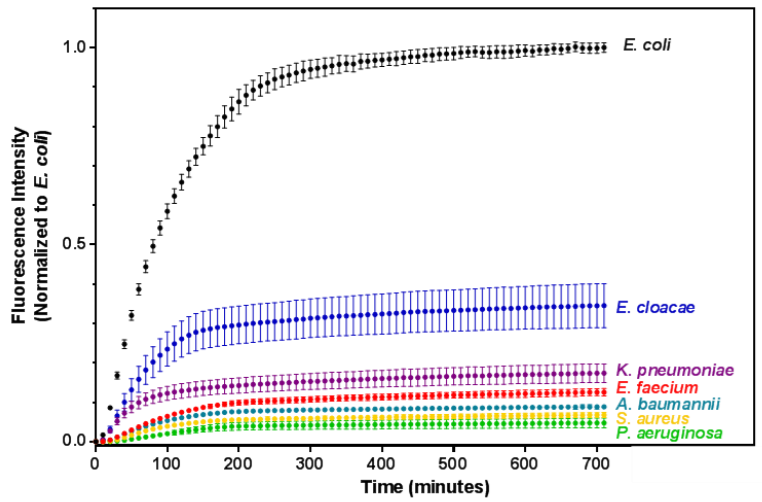

Figure 4. Translation and trans-translation kinetics over time. A) Translation kinetics over time: the increase in fluorescence is directly linked to translation. B) Trans-translation kinetics over time using ESKAPE ribosomes. All results are shown as means \pm standard deviation and normalized to $E$. coli.

Despite these rather poor translation rates, fluorescence was easily detected, so we also performed trans-translation experiments using ESKAPE ribosomes (Fig. 4B). The goal was to improve the levels of the trans-translation signals previously recovered, but more importantly to obtain a positive result for $P$. aeruginosa. The results were finally conclusive for that bacteria, which gave a fluorescent signal of $\sim 10 \%$ compared to the control. This positive result is certainly due to the quite efficient translation obtained with these ribosomes (Figure 4A). On the other hand, the trans-translation levels of the other bacteria did not improve, and were even lower in S. aureus. This is surely due to the fact that the PURExpress system is based on only 
JBC "Methods and Resources" submission. Thépaut et al., Evaluation of trans-translation in ESKAPE bacteria

E. coli translation factors, and their low count limits their handling of canonical translation (see Fig. 4A) or specific tmRNAs (e.g. tmRNA aminoacylation by E. coli AlaRS or tmRNA-SmpB transport by E. coli EF-Tu-GTP).

\section{Discussion}

Here we describe the use of GFP as a reporter for safe measurement of the trans-translation activity of the six ESKAPE systems in a cell-free protein synthesis system. The various combinations we evaluated (four for each ESKAPE pathogen) have yielded different interesting strategies for the disruption of trans-translation (Fig. 5).

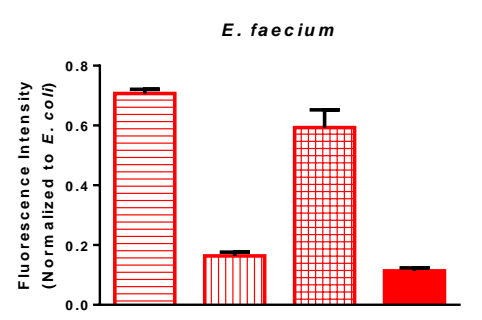

A. baumannii
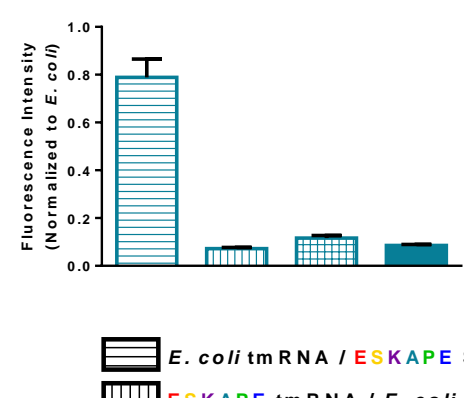

E. coli tmRNA / ESKAPESmpB / E. coli Ribosome

WDIDSKAPE tmRNA / E. colismpB / E. coli Ribosome
S. aureus

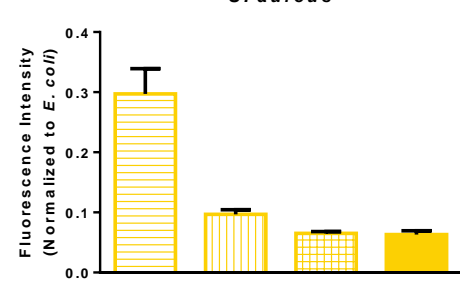

P. aeruginosa

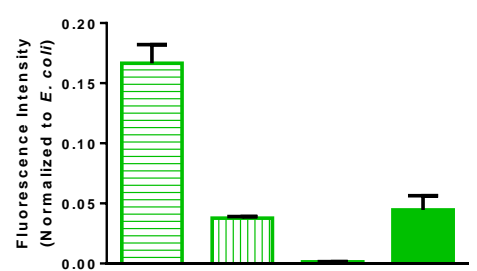

K. pneumoniae

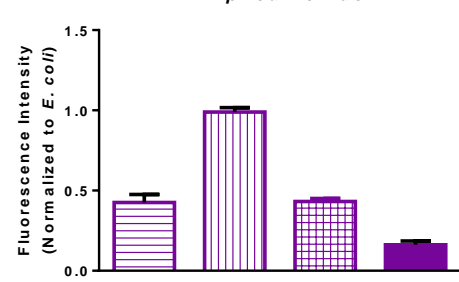

E. cloacae

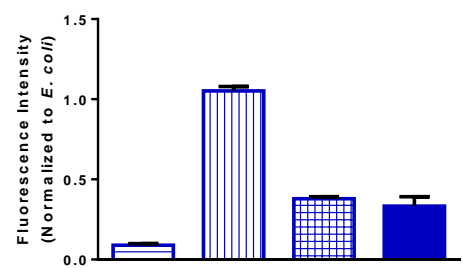

Figure 5: Quantification of in vitro trans-translation. Normalized fluorescence obtained in heterologous and homologous systems are shown at 310 minutes of incubation and reassembled by species. The results were normalized to the E. coli conditions and are shown as means \pm standard deviations.

The molecules being investigated for the development of new anti-trans-translation antibiotics will have different ways of interfering with tmRNA-SmpB binding to stalled ribosomes. They could disrupt tmRNA-SmpB interactions, or they could prevent interactions between the 
JBC "Methods and Resources" submission. Thépaut et al., Evaluation of trans-translation in ESKAPE bacteria

complex and the ribosome, such as by blocking the entrance of SmpB entirely or by preventing the passage of the complex through the bridges which have to be open during the process. Therefore, it is of great interest to have the ability to evaluate the targeting of the three main actors (tmRNA, SmpB, and the ribosome) independently as well as in each ESKAPE system. Of the 24 combinations we tested, 23 exhibited a signal strong enough for evaluating the possible activity of inhibitors. The only one that did not was the $P$. aeruginosa tmRNA-SmpB complex when used with E. coli ribosomes. We first suspected that the tmRNA H5 helix, inspired from the E. coli helix (Fig. 1B), might somehow have altered its activity. Therefore, to avoid any possible effects of the helical rearrangement, we constructed and tested new

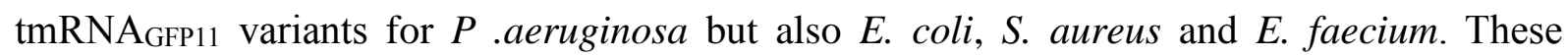
tmRNAGFP11 22 constructs all have the full sequence that encodes the eleventh domain of GFP upstream from the natural H5 helix (Supp. Fig. 2). However, these variants did not have improved fluorescence, and $P$. aeruginosa still did not emit signals. We can thus exclude the idea that the different structural features between the P. aeruginosa and E. coli ribosomes (Halfon et al., 2019) are important enough to prevent the correct process from occurring.

To permit the high-throughput screening of chemical compounds in multi-well microplates it was important to lower average screening costs of the current assay. To enable this, we decreased the reaction scale of the assays by reducing the final reaction volumes down to a microliter scale. Proof-of-concept experiments were performed with E. coli in final volumes of $1 \mu \mathrm{l}$ using a MANTIS liquid-handler instrument (Formulatrix), and the resulting signals were strong enough to allow for the easy detection of trans-translational activity (not shown). Indeed, the objective of this study was to create a non-hazardous in vitro screening system for evaluating trans-translation in ESKAPE pathogens, and to miniaturize it for HTS applications, and the assays we performed were convincing. The system will clearly be very effective for benchmarking the effects of new antibiotic compounds that target trans-translation 
JBC "Methods and Resources" submission. Thépaut et al., Evaluation of trans-translation in ESKAPE bacteria

in highly pathogenic bacteria, as well as aiding us to better understand the trans-translation process in these bacteria. Its flexibility in the choice of target bacterial species and the possibility to for varying the combinations of tmRNA, SmpB, and ribosomes are advantageous, making the identification of new specific antimicrobial inhibitors easier. Ongoing experiments in our laboratory are using this to screen large chemical and natural product libraries for drug discovery.

\section{Experimental Procedures}

\section{In silico analysis}

Complete genomes were retrieved from the NCBI database (March 2020). Chromosomes and plasmids (when present) were studied separately. GenBank files were first searched based on their textual annotation entries, using the keywords 'ArfA,' 'yhdL,' and 'alternative ribosomerescue factor' (for ArfA), or 'ArfB,' 'yaeJ,' 'ribosome-associated protein,' and 'peptidyl-tRNA hydrolase' (for ArfB). Missing loci were checked using BlastN, BlastP, and tBlastN similaritydetection strategies (Altschul et al., 1990) as well as comparative genomics, with synteny analysis done using progressiveMauve (Darling et al., 2010). All retrieved loci were compared using the Reciprocal Best Hits method, and InterProScan (Jones et al., 2014) was used on the corresponding proteins to check for the presence of the IPR005589/ PF03889 (ArfA) and IPR000352/PF00472 (ArfB) domains. Frameshifted loci were indicated as annotated in the GenBank files. Finally, the presence and absence of K09890 (ArfA) and K15034 (ArfB) were checked in the KEGG ORTHOLOGY database (Kanehisa et al., 2016).

\section{Plasmid construction and preparation}

For each ESKAPE tmRNA, the internal open reading frame was replaced by the eleventh domain of the superfolder GFP (sfGFP) preceded by the first conserved alanine of native tmRNA. In order to preserve the H5 helix, compensatory mutations were added (Fig. 2B). 
JBC "Methods and Resources" submission. Thépaut et al., Evaluation of trans-translation in ESKAPE bacteria

Additionally, the sequences were designed to carry a T7 promotor sequence in the 5 '-end in order to realize transcription in vitro. Note that the tmRNA 3 '-end natural sequences from $E$. faecium (UUG) and S. aureus (UAU) were replaced by CCA so that the E. coli AlaRS could correctly aminoacylate them.

We also produced tmRNA ${ }_{\mathrm{GPP} 11} \mathrm{~V} 2$ variants for E. coli, P.aeruginosa, S.aureus and E. faecium species. This tmRNA ${ }_{\mathrm{GFP} 11}$ series carries the full sequence encoding the eleventh domain of GFP upstream from the E. coli $\mathrm{H} 5$ helix (Supp. Fig. 2). In order to obtain mature tmRNA $\mathrm{GFP}_{11}$ by in vitro transcription, the tmRNA $\mathrm{GFP}_{11}$ and tmRNA $\mathrm{GFP}_{11} \mathrm{~V} 2$ ESKAPE sequences were synthesized and cloned into the pUC19 vector between the HindIII and BamHI restriction sites (Supp. Table 1). For each ESKAPE SmpB, GenScript synthesized the sequences with codon optimization for E. coli, cloning them into the pET22b(+) vector between the NdeI and XhoI restriction sites to add a 6His histidine tag (Supp. Table 2). The generated plasmids, pUC19ESKAPEtmRNA ${ }_{\text {GFP11 }}$ and pET22b+ESKAPESmpB (Supp. Table 5), were amplified in E. coli NM522 cells then extracted using a NucleoBond Xtra Midi kit (Macherey-Nagel). Quantification was performed using a SimpliNano spectrophotometer (Biochrom).

\section{SmpB purification}

The bacterial cultures and SmpB purification were all done as previously described (Guyomar et al., 2020). His-tagged E. coli and ESKAPE SmpB proteins (Supp. Table 2) were expressed from the $\mathrm{pF} 1275$ and the $\mathrm{pET} 22 \mathrm{~b}+\mathrm{ESKAPE}$ SmpB vectors under the control of a T7 promoter in BL21(DE3)4ssrA cells (Cougot et al., 2014). Briefly, BL21(DE3) $\Delta s s r A$ cells were grown in lysogeny broth (LB) at $30{ }^{\circ} \mathrm{C}$ supplemented with ampicillin $(100 \mu \mathrm{g} / \mathrm{ml})$ and kanamycin $(50$ $\mu \mathrm{g} / \mathrm{ml})$. Protein expression was induced in the exponential phase $\left(O D_{600}=0.6\right)$ with $0.1 \mathrm{mM}$ isopropyl- $\beta$-D-1-thiogalactopyranoside (IPTG) overnight at $16{ }^{\circ} \mathrm{C}$. Cells were harvested and washed, then resuspended in lysis buffer $(50 \mathrm{mM}$ HEPES-KOH, $200 \mathrm{mM} \mathrm{KCl}, 20 \mathrm{mM}$ imidazole, and $1 \mathrm{mM}$ DTT $\mathrm{pH}$ 7.5). Cell lysis was performed using a French press, and the 
JBC "Methods and Resources" submission. Thépaut et al., Evaluation of trans-translation in ESKAPE bacteria

lysate was centrifuged at $15,000 \mathrm{rpm}$ for 45 minutes at $4{ }^{\circ} \mathrm{C}$ in a Beckman J2-MC with a JA-17 rotor. The supernatant was then filtrated $(0.2 \mu \mathrm{m})$ and injected onto a Ni-NTA sepharose column (HisTrap FF, GE Healthcare) previously equilibrated with the lysing buffer. The column was washed with $100 \mathrm{ml}$ lysis buffer and $50 \mathrm{ml}$ washing buffer (50 mM HEPES-KOH, $200 \mathrm{mM} \mathrm{KCl}, 1 \mathrm{M} \mathrm{NH}_{4} \mathrm{Cl}$, imidazole $20 \mathrm{mM}$, and $1 \mathrm{mM}$ DTT $\mathrm{pH}$ 7.5) before elution with 500 mM imidazole. Finally, a 10kDa Amicon Ultra centrifugal filter (Merck Millipore) was used to concentrate the fractions containing pure $\mathrm{SmpB}$, changing the buffer to a concentration buffer (50 mM HEPES-KOH, $100 \mathrm{mM} \mathrm{KCl,} 10 \%$ glycerol, and $1 \mathrm{mM}$ DTT pH 7.5). In order to visualize SmpB, 50 pmol of denatured proteins was analyzed on 15\% SDS-PAGE gels. Proteins were detected using InstantBlue protein stain (Expedeon) according to the supplier's instructions.

\section{tmRNA $A_{G F P 11}$ production}

E. coli and ESKAPE tmRNA GFP11 $_{1}$ were produced as previously described (Guyomar et al.,

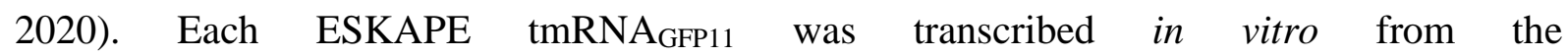
pUC19ESKAPEtmRNAGFP11 plasmids. To generate the 3' end needed for aminoacylation by AlaRS, the plasmid $(10 \mu \mathrm{g})$ was completely digested by NEB BsmBI or EarI restriction enzymes (Supp. Table 5). After phenol/chloroform extraction, the purified digested plasmid was precipitated, and the resulting pellets resuspended in $40 \mu 1$ nuclease-free water. A MEGAscript 77 transcription kit (Thermo Fisher Scientific) was used to produce each ESKAPE tmRNA $_{\text {GFP11 }}$ before its purification using the corresponding MEGAclear kit. Denatured tmRNA $_{\text {GFP11 }}$ was checked by electrophoresis on $8 \%$ Urea-PAGE gels, stained with ethidium bromide, and visualized under ultraviolet light.

\section{DNA templates and oligonucleotide production}

For trans-translation assays, the nonstop GFP1-10 sequence was produced by PCR using primers \#1 and 2 and Q5 High-Fidelity DNA Polymerase (NEB) with pETGFP 1-10 vector as 
JBC "Methods and Resources" submission. Thépaut et al., Evaluation of trans-translation in ESKAPE bacteria

a template (Cabantous et al., 2006; Supp. Table 3 and 4). For translation assays, primers \#1 and \#3 from the same template were used to amplify sfalaGFP, the superfolder GFP having an additional conserved alanine between the sfGFP1-10 and sfGFP11 domains (Supp. Table 3 and 4). The resulting PCR products were purified using a QIAquick PCR Purification Kit (Qiagen) and checked by agarose electrophoresis. Both PCR products have a T7 promoter upstream from their coding sequences. Antisense oligonucleotide "A" was supplied by Eurofins (Supp. Table $3)$.

\section{ESKAPE ribosome purification}

Ribosomes were purified from Acinetobacter baumannii (clinical isolate); Staphylococcus aureus (clinical isolate); Pseudomonas aeruginosa (ATCC 27853); Enterobacter cloacae (clinical isolate); Klebsiella pneumoniae (clinical isolate); and Enterococcus faecium (HM1070). From an overnight starter culture, 6-9 L of LB medium were inoculated to reach an $\mathrm{OD}_{600}$ of 0.05 , then stirred at $150 \mathrm{rpm}$ at $37^{\circ} \mathrm{C}$. Bacterial growth was stopped when the $\mathrm{OD}_{600}$ reached 0.8 to 1.0 . The cells were then centrifuged at $4,000 \mathrm{rpm}$ for 20 minutes at $4{ }^{\circ} \mathrm{C}$. Pellets (around $2 \mathrm{~g} / \mathrm{L}$ of culture) were washed in a lysis buffer (20 mM Tris- $\mathrm{HCl} \mathrm{pH} 7.5,20 \mathrm{mM} \mathrm{MgCl}$, $200 \mathrm{mM} \mathrm{NH}_{4} \mathrm{Cl}, 0.1 \mathrm{mM}$ EDTA, and $6 \mathrm{mM} \beta$-mercaptoethanol), centrifuged at 4,000 rpm for 15 minutes at $4{ }^{\circ} \mathrm{C}$, and kept overnight at $-80{ }^{\circ} \mathrm{C}$. Pellets were then suspended in a Potter homogenizer in another lysis buffer complemented with $1 \mathrm{mM} \mathrm{CaCl}_{2}$. Cells were lysed in a French press at $1.0 \mathrm{kbar}$. To remove cellular debris, the lysates were centrifuged using a type $50.2 \mathrm{Ti}$ rotor at $18,200 \mathrm{rpm}$ for 30 minutes at $4{ }^{\circ} \mathrm{C}$. The superficial pellet layer was then discarded, and the pellet resuspended in lysis buffer. Ribosomes were isolated by centrifuging lysates on a $30 \%$ sucrose cushion at $31,500 \mathrm{rpm}$ for 19 hours at $4{ }^{\circ} \mathrm{C}$. The superficial layer of pellets was again discarded, leaving only the transparent pellets which were then resuspended in conservation buffer (20 mM Tris- $\mathrm{HCl} \mathrm{pH} 7.5,10 \mathrm{mM} \mathrm{MgCl}_{2}, 50 \mathrm{mM} \mathrm{NH}_{4} \mathrm{Cl}, 0.1 \mathrm{mM}$ EDTA, and $6 \mathrm{mM} \beta$-mercaptoethanol). Any remaining contaminants were removed by a final 
JBC "Methods and Resources" submission. Thépaut et al., Evaluation of trans-translation in ESKAPE bacteria

centrifugation at $18,200 \mathrm{rpm}$ for 1 hour at $4{ }^{\circ} \mathrm{C}$. Ribosomes were concentrated using a Centricon (Merck Millipore) with a cut-off of $100 \mathrm{~K}$, flash-frozen in nitrogen, and conserved at $-80{ }^{\circ} \mathrm{C}$.

\section{Trans-translation assays}

In vitro trans-translation assays were performed using the PURExpress In Vitro Protein Synthesis and $\Delta$ Ribosome kits (New England Biolabs). For trans-translation assays, PURExpress was supplemented by $62.5 \mathrm{ng}$ purified PCR product encoding for nonstop sfGFP110, 12.5 pmol tmRNA ${ }_{\mathrm{GFP} 11}, 25 \mathrm{pmol} \mathrm{SmpB}$, and 50 pmol antisense A. Where necessary $(\Delta$ Ribosome), 6.725 pmol ribosomes were also added. These reactions were performed in a final reaction volume of $10 \mu \mathrm{L}$, with PURExpress diluted by a final factor of 1.6 with Buffer III (HEPES-KOH 5mM pH7.5, MgOAc 9mM, NH4Cl 10mM, KCl 50mM, and DTT 1mM). A Step One Plus PCR system (Applied Biosystems) was used for incubation at $37^{\circ} \mathrm{C}$ as well as for fluorescence measurements over 710 minutes.

\section{Translation assays}

In vitro translation assays were performed using a PURExpress $\Delta$ Ribosome kit. To produce the sfalaGFP, the PURExpress $\Delta$ Ribosome was diluted to a final factor of 1.6 with Buffer III, to which was added $62.5 \mathrm{ng}$ purified PCR product and $6.725 \mathrm{pmol}$ of the appropriate ribosomes. The translation reactions were incubated at $37^{\circ} \mathrm{C}$, and fluorescence was measured over 710 minutes using a Step One Plus.

\section{Acknowledgments}

The authors are particularly grateful to Axel Innis and Anne-Xander van der Stel for sharing their Mantis experiment expertise and to Charlotte Guyomar for insightful comments on the manuscript. We thank Sylvie Georgeault and Fanny Demay for their help in purifying E. faecium ribosomes.

Funding and additional information 
bioRxiv preprint doi: https://doi.org/10.1101/2020.12.16.423090; this version posted December 17, 2020. The copyright holder for this preprint (which was not certified by peer review) is the author/funder. All rights reserved. No reuse allowed without permission.

JBC "Methods and Resources" submission. Thépaut et al., Evaluation of trans-translation in ESKAPE bacteria

395

396

397

398

399

400

401

402

403

404

405

406

407

408

409

410

411

412

413

414

415

416

417

418

419

420

421

422

423

424

425

426

427

428

429

430

431

432

This work was supported by the Agence Nationale pour la Recherche as part of the EU's Joint Programming Initiative on Antimicrobial Resistance project (JPIAMR) project "Ribotarget - Development of novel ribosome-targeting antibiotics" as well as by SATT Ouest-Valorisation (DV 2552 and DV 3506).

Author contributions

M.T. cloned and purified the SmpB and tmRNA variants and performed and analyzed the trans-translation in vitro assays.

R.C.D.S. performed trans-translation in vitro assays. E.V. purified ribosomes from A. baumannii, E. cloacae, K. pneumoniae,

P. aeruginosa, and S. aureus. F.B.H. performed in silico analysis of ArfA and ArfB in bacterial genomes. R.G. designed the study. E.E., D.B., and R.G. supervised the project. M.T. and R.G. wrote the manuscript, and all authors approved its final version

\section{Conflict of interest}

Reynald Gillet is co-inventor of the system described here (patent application \#EP/2018/063780).

\section{References}

1- Rice, L. B. (2008) Federal funding for the study of antimicrobial resistance in nosocomial pathogens: no ESKAPE. J. Infect. Dis. 197, 1079-1081

2- Tacconelli, E., and Magrini, N. (2017) Global priority list of antibiotic-resistant bacteria to guide research, discovery, and development of new antibiotics World Health Organization

3- Santajit, S., Indrawattana, N. (2016) Mechanisms of Antimicrobial Resistance in ESKAPE Pathogens. Biomed Res Int. 2475067

4- Giudice E, Macé K, Gillet R. (2014) Trans-translation exposed: understanding the structures and functions of tmRNA-SmpB. Front Microbiol. 5,113.

5- Hudson, C.M., and Williams, K.P. (2015) The tmRNA website. Nucleic Acids Res. 43 (Database issue):D138-40.

6- Schönhuber, W., Le Bourhis, G., Tremblay, J., Amann, R., Kulakauskas, S. (2001). Utilization of tmRNA sequences for bacterial identification. BMC Microbiol. 1, 20.

7- Keiler, K.C., and Feaga, H.A. Resolving nonstop translation complexes is a matter of life or death. (2014) J Bacteriol. 196, 2123-30.

8- Himeno, H., Nameki, N., Kurita, D., Muto, A., Abo, T. (2015) Ribosome rescue systems in bacteria. Biochimie. 114, 102-12.

9- Goralski, T.D.P., Kirimanjeswara, G.S., Keiler, K.C. (2018) A New Mechanism for Ribosome Rescue Can Recruit RF1 or RF2 to Nonstop Ribosomes. mBio. 9, e02436-18.

10- Shimokawa-Chiba, N., Müller, C., Fujiwara, K., Beckert, B., Ito, K., Wilson, D.N., Chiba, S. (2019) Release factor-dependent ribosome rescue by BrfA in the Gram-positive bacterium Bacillus subtilis. Nat. Commun. 10:5397.

11- Li, J., Ji, L., Shi, W., Xie, J., Zhang, Y. (2013) Trans-translation mediates tolerance to multiple antibiotics and stresses in Escherichia coli. J. Antimicrob. Chemother. 68, 2477-81. 
bioRxiv preprint doi: https://doi.org/10.1101/2020.12.16.423090; this version posted December 17, 2020. The copyright holder for this preprint (which was not certified by peer review) is the author/funder. All rights reserved. No reuse allowed without permission.

JBC "Methods and Resources" submission. Thépaut et al., Evaluation of trans-translation in ESKAPE bacteria

12- Ramadoss, N.S., Alumasa, J.N., Cheng, L., Wang, Y., Li, S., Chambers, B.S., Chang, H., Chatterjee, A.K., Brinker, A., Engels, I.H., et al. (2013) Small molecule inhibitors of trans-translation have broad-spectrum antibiotic activity. Proc. Natl. Acad. Sci. U. S. A., 110, 10282-10287.

13- Macé,K., Demay,F., Guyomar,C., Georgeault,S., Giudice,E., Goude,R., Trautwetter,A., Ermel,G., Blanco,C. and Gillet,R. (2017) A Genetic Tool to Quantify trans-Translation Activity in Vivo. J. Mol. Biol., 429, 3617-3625.

14- Brunel,R., Descours,G., Durieux,I., Doublet,P., Jarraud,S. and Charpentier,X. (2018) KKL-35 Exhibits Potent Antibiotic Activity against Legionella Species Independently of transTranslation Inhibition. Antimicrob. Agents Chemother. 62, e01459-17.

15- Shi, W., Zhang, X., Jiang, X., Yuan, H., Lee, J.S., Barry, C.E. 3rd, Wang, H., Zhang, W., Zhang, Y. (2011) Pyrazinamide inhibits trans-translation in Mycobacterium tuberculosis. Science. 333, 1630-2.

16- Dillon, N.A., Peterson, N.D., Feaga, H.A., Keiler, K.C., Baughn, A.D. (2017) Anti-tubercular Activity of Pyrazinamide is Independent of trans-Translation and RpsA. Sci. Rep. 7, 6135.

17- Osterman, I.A., Bogdanov, A.A., Dontsova, O.A., Sergiev, P.V. (2016) Techniques for Screening Translation Inhibitors. Antibiotics (Basel). 5

18- Guyomar, C., Thépaut, M., Nonin-Lecomte, S., Méreau, A., Goude, R., Gillet, R. (2020) Reassembling green fluorescent protein for in vitro evaluation of trans-translation. Nucleic Acids Res. 48(4): 222

19- Barends S, Wower J, Kraal B. (2000) Kinetic parameters for tmRNA binding to alanyl-tRNA synthetase and elongation factor Tu from Escherichia coli. Biochemistry. 39(10):2652-8.

20- Shimizu,Y., Inoue,A., Tomari,Y., Suzuki,T., Yokogawa,T., Nishikawa,K., Ueda,T. (2001) Cell-free translation reconstituted with purified components. Nat. Biotechnol., 19, 751-755

21- Shimizu, Y., Ueda, T. The role of SmpB protein in trans-translation. (2002) FEBS Lett.514, 74-7.

22- Karzai, A.W., Susskind, M.M., Sauer, R.T. SmpB, a unique RNA-binding protein essential for the peptide-tagging activity of SsrA (tmRNA). (1999) EMBO J. 18:3793-9.

23- Liu, P., Chen, Y., Wang, D., Tang, Y., Tang, H., Song, H., Sun, Q., Zhang, Y., Liu, Z. (2016) Genetic Selection of Peptide Aptamers That Interact and Inhibit Both Small Protein B and Alternative Ribosome-Rescue Factor A of Aeromonas veronii C4. Front. Microbiol. 7, 1228.

24- Halfon, Y., Jimenez-Fernandez, A., La Rosa, R., Espinosa Portero, R., Krogh Johansen, H., Matzov, D., Eyal, Z., Bashan, A., Zimmerman, E., Belousoff, M., Molin, S., Yonath, A. (2019) Structure of Pseudomonas aeruginosa ribosomes from an aminoglycoside-resistant clinical isolate. Proc. Natl. Acad. Sci. U S A. 116, 22275-22281.

25- Altschul, S.F., Gish, W., Miller, W., Myers E.W. and Lipman, D.J. (1990) Basic Local Alignment Search Tool. J. Mol. Biol. 215, 403-410.

26- Darling, A.E., Mau, B., and Perna N.T. (2010) progressiveMauve: multiple genome alignment with gene gain, loss and rearrangement. PLoS One. 5(6):e11147

27- Jones, P., Binns, D., Chang, H.Y., Fraser, M., Li, W., McAnulla, C., McWilliam, H., Maslen, J., Mitchell, A., Nuka, G., Pesseat, S., Quinn, A.F., Sangrador-Vegas, A., Scheremetjew, M., Yong, S.Y., Lopez, R. and Hunter, S. (2014). InterProScan 5: genome-scale protein function classification. Bioinformatics. 30, 1236-1240.

28- Kanehisa, M., Sato, Y., Kawashima, M., Furumichi, M. and Tanabe, M. (2016) KEGG as a reference resource for gene and protein annotation. Nucleic Acids Res. 44(D1):D457-62.

29- Cougot,N., Molza,A.-E., Delesques,J., Giudice,E., Cavalier,A., Rolland,J.-P., Ermel,G., Blanco,C., Thomas,D. and Gillet,R. (2014) Visualizing compaction of polysomes in bacteria. J. Mol. Biol., 426,377-388.

30- Cabantous,S. and Waldo,G.S. (2006) In vivo and in vitro protein solubility assays using split GFP. Nat. Methods, 3, 845-85 
bioRxiv preprint doi: https://doi.org/10.1101/2020.12.16.423090; this version posted December 17, 2020. The copyright holder for this preprint (which was not certified by peer review) is the author/funder. All rights reserved. No reuse allowed without permission.

JBC “Methods and Resources" submission. Thépaut et al., Evaluation of trans-translation in ESKAPE bacteria

\section{A - Phylogenetic comparison of tmRNA sequences}

485

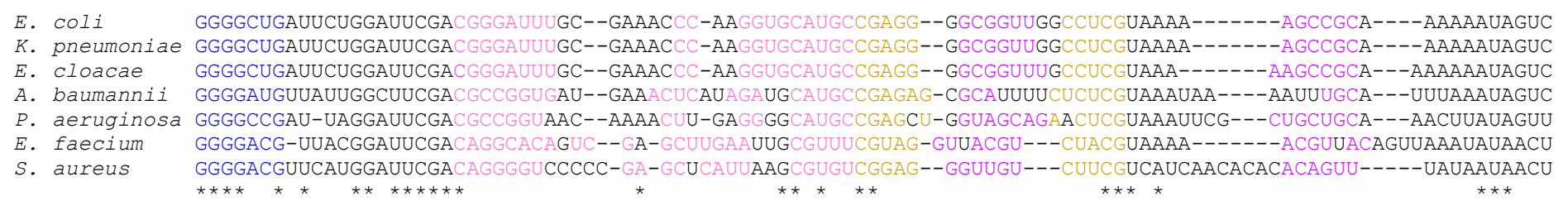

GGGGCUGAUUCUGGAUUCGACGGGAUUUGC--GAAACCC-AAGGUGCAUGCCGAGG--GGCGGUUGGCCUCGUAAAA-------AGCCGCA----AAAAAUAGUC 89 GGGGCUGAUUCUGGAUUCGACGGGAUUUUGC--GAAACCC-AAGGUGCAUGCCGAGG--GGCGGUUGGCCUCGUAAAA-------AGCCGCA----AAAAAUAGUC GGGGCCGAU-UAGGAUUCGACGCCGGUAAC--AAAACUU-GAGGGGCAUGCCGAGCU-GGUAGCAGAACUCGUAAAUUCG---CUGCUGCA---AACUUAUAGUU (1)

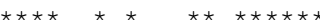

$\star \star \star \star *$ $\star \star \star$

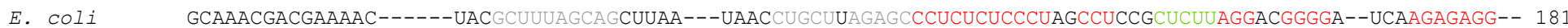

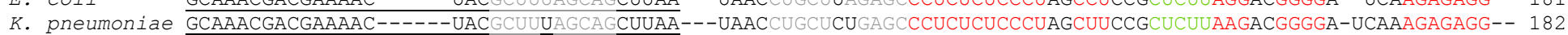

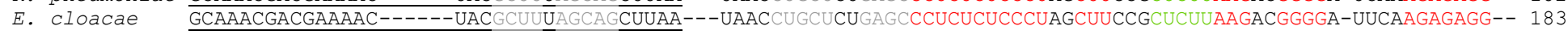

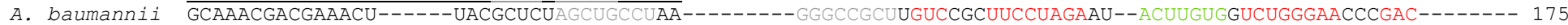

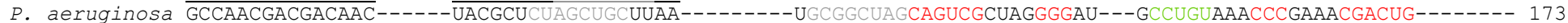

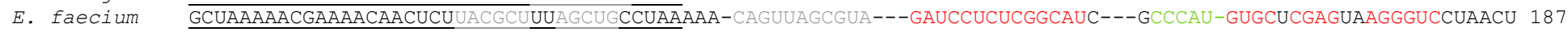

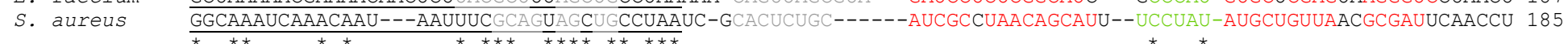

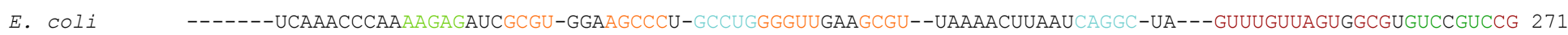

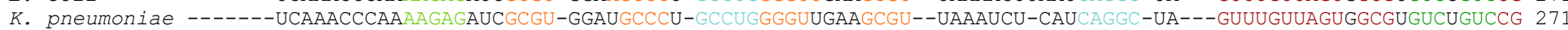

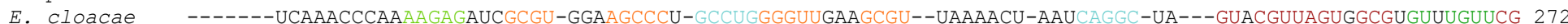

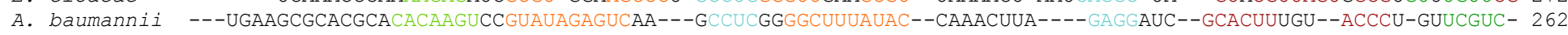

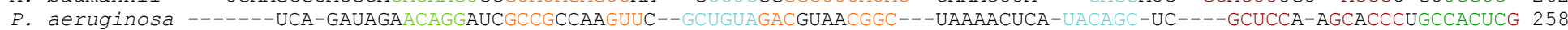
F. faecium UUA-----------GUTCGAUAC-GUUUUCAACUUUUCC-GUTUTU--AAGUUTCAAAAAGAGAACAU----CAGAC-UAGCGAUACAGAA--UGCCU-GUCACUCG 268

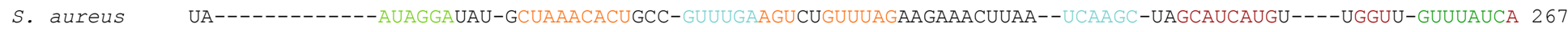

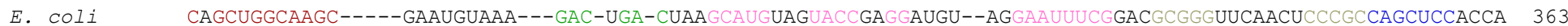

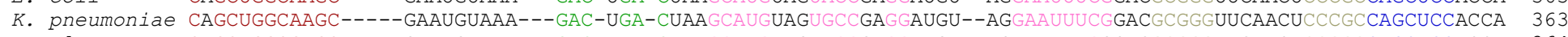

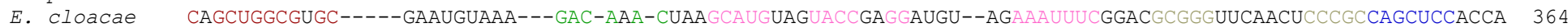

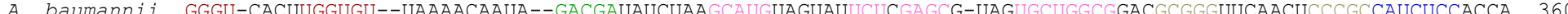

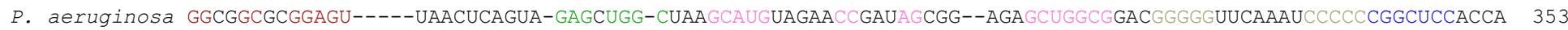

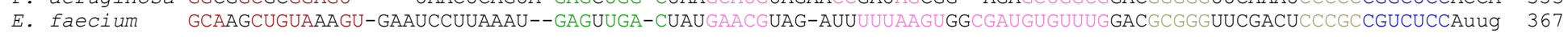

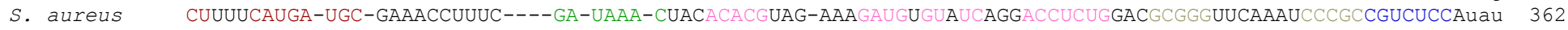

Adapted from the tmRNA Website by Kelly Williams and Corey Hudson (All tmRNA Alignment 08JUL-2014), with base-pairing color-coded (P1, P2, P3, P4, MLD, P5, P6, P7, P8, P9, P10, P11, and $\mathrm{P} 12)$. The predicted reading frame for the proteolysis-inducing peptide tag is underlined, and the portions of the expected 3' CCA tail that are not encoded in the genome are lowercase.

\section{A - Phylogenetic comparison of SmpB amino-acid sequences}


bioRxiv preprint doi: https://doi.org/10.1101/2020.12.16.423090; this version posted December 17, 2020. The copyright holder for this preprint (which was not certified by peer review) is the author/funder. All rights reserved. No reuse allowed without permission.

JBC "Methods and Resources" submission. Thépaut et al., Evaluation of trans-translation in ESKAPE bacteria

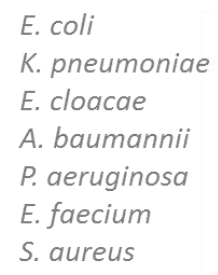

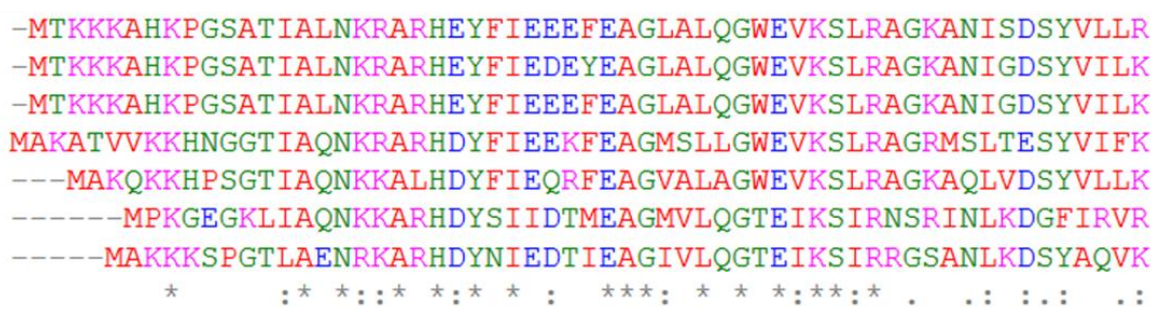

NAWCKVKIGVAKGKKQHDKRSDIKEREWQVDKARIMKNAHR-

160

NAWCKVKIGVAKGKKQHDKRTDLKDREWALDKARIMKHAGR-

160 NAWCKVKVGVAKGKKQHDKRTDLKEREWQLDKARIMKNAGR- 160 GHLVKLEIALVKGKQLHDKRATEKERDWQRDKARIFHK---- 158 KHLVKCEIALAKGKKDFDKRHTEKERDSDREIQRAMRHGKDD 159 NGYAKVLIGLAKGKKSYDKREDLKRKDIDRQIDRTLKNFSR- 154 HGHCKVLLGVARGKKKYDKRQALKEKAVKRDVARDMKARY-- 154

Residue properties are color-coded: small [small+ hydrophobic (incl.aromatic -Y)]; acidic; basic - H; Hydroxyl + sulfhydryl + amine $+G$, unusual amino or imino acids, etc. Key: *, positions having a single and fully conserved residue; ., weakly similar properties conserved between groups; :, strongly similar properties conserved between groups.

Supplementary Figure 1. Phylogenetic comparison of SmpBs and tmRNAs from ESKAPE pathogens and $\boldsymbol{E}$. coli. A) Shown here are the SmpB amino acid sequences (Clustal Omega) and B) the RNA sequences of tmRNAs from ESKAPE and E. coli bacteria. 
JBC "Methods and Resources" submission. Thépaut et al., Evaluation of trans-translation in ESKAPE bacteria

A

508

509

510

511

512

513

514

515

516

517

518

519

520

521
B

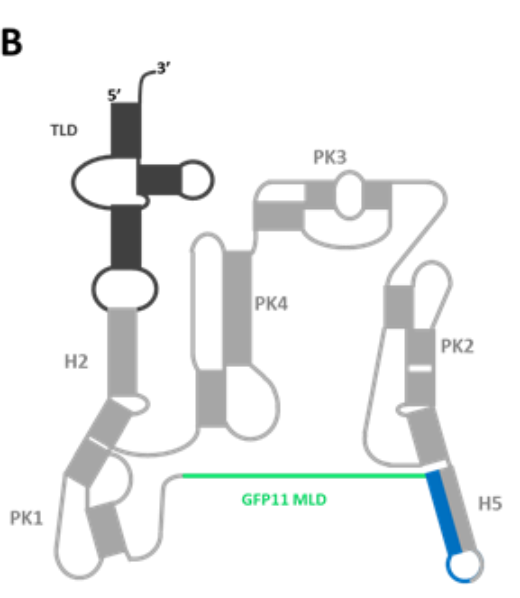

Supplementary Figure 2. (A) Wild-type (WT) tmRNA. (B) Version 2 mutated tmRNA $A_{\text {GPP11. An }}$ engineered MLD encoding the eleventh GFP domain is green, the WT 3 '-end MLD is blue, and the WT

H5 helix is gray.

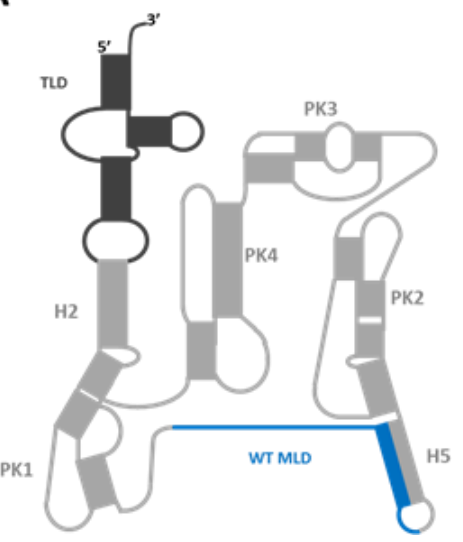


bioRxiv preprint doi: https://doi.org/10.1101/2020.12.16.423090; this version posted December 17, 2020. The copyright holder for this preprint (which was not certified by peer review) is the author/funder. All rights reserved. No reuse allowed without permission.

JBC “Methods and Resources" submission. Thépaut et al., Evaluation of trans-translation in ESKAPE bacteria

522 Supplementary Table 1: E. coli and ESKAPE tmRNA ${ }_{\mathrm{GFP} 11}$ sequences for trans-translation in vitro. The 523 eleventh domain is light green and the compensatory mutations forming the helix H5 are darker green.

\begin{tabular}{|c|c|}
\hline Species and Accession & tmRNA $A_{G F P 11}$ sequence \\
\hline $\begin{array}{l}\text { E. faecium } \\
\text { NC } 017960.1 / 1726235- \\
\underline{1726601}\end{array}$ & $\begin{array}{l}\text { GGGGACGUUACGGAUUCGACAGGCACAGUCGAGCUUGAAUUGCGUUUCGUAGGUUACGUCUAC } \\
\text { GUAAAAACGUUACAGUUAAAUAUAACUGCACGUGACCACAUGGUCCUUCAUGAGUACGUAAAU } \\
\text { GCUGCUGGGAUUACAUAAUAACCUAAUCCUAGCGAUCCUCUCGGCAUCGCCCAUGUGCUCGAG } \\
\text { UAAGGGUCCUAACUUUAGUGGGAUACGUUUCAACUUUCCGUCUGUAAGUUGAAAAAGAGAACA } \\
\text { UCAGACUAGCGAUACAGAAUGCCUGUCACUCGGCAAGCUGUAAAGUGAAUCCUUAAAUGAGUU } \\
\text { GACUAUGAACGUAGAUUUUUAAGUGGCGAUGUGUUUGGACGCGGGUUCGACUCCCGCCGUCUC } \\
\text { CACCA }\end{array}$ \\
\hline $\begin{array}{l}\text { S. aureus } \\
\text { NZ_GG774480.1/110721 } \\
\underline{4-1106853}\end{array}$ & $\begin{array}{l}\text { GGGGACGUUCAUGGAUUCGACAGGGGUCCCCCGAGCUCAUUAAGCGUGUCGGAGGGUUGUCUU } \\
\text { CGUCAUCAACACACACAGUUUAUAAUAACUGCACGUGACCACAUGGUCCUUCAUGAGUACGUA } \\
\text { AAUGCUGCUGGGAUUACAUAAUAACCUAAUCCUAGCAUCGCCUAACAGCAUUUCCUAUAUGCU } \\
\text { GUUAACGCGAUUCAACCUUAAUAGGAUAUGCUAAACACUGCCGUUUGAAGUCUGUUUAGAAGA } \\
\text { AACUUAAUCAAGCUAGCAUCAUGUUGGUUGUUUAUCACUUUUCAUGAUGCGAAACCUUUCGAU } \\
\text { AAACUACACACGUAGAAAGAUGUGUAUCAGGACCUCUGGACGCGGGUUCAAAUCCCGCCGUCU } \\
\text { CCACCA }\end{array}$ \\
\hline $\begin{array}{l}\text { K. pneumoniae } \\
\text { NC 017540.1/3743434- } \\
\underline{3743796}\end{array}$ & $\begin{array}{l}\text { GGGGCUGAUUCUGGAUUCGACGGGAUUUGCGAAACCCAAGGUGCAUGCCGAGGGGCGGUUGGC } \\
\text { CUCGUAAAAAGCCGCAAAAAAUAGUCGCACGUGACCACAUGGUCCUUCAUGAGUACGUAAAUG } \\
\text { CUGCUGGGAUUACAUAAUAACCUAAUCCUAGCCCUCUCUCCCUAGCUUCCGCUCUUAAGACGG } \\
\text { GGAUCAAAGAGAGGUCAAACCCAAAAGAGAUCGCGUGGAUGCCCUGCCUGGGGUUGAAGCGUU } \\
\text { AAAUCUCAUCAGGCUAGUUUGUUAGUGGCGUGUCUGUCCGCAGCUGGCAAGCGAAUGUAAAGA } \\
\text { CUGACUAAGCAUGUAGUGCCGAGGAUGUAGGAAUUUCGGACGCGGGUUCAACUCCCGCCAGCU } \\
\text { CCACCA }\end{array}$ \\
\hline $\begin{array}{l}\text { A. baumannii } \\
\text { NZ KB849843.1/157403 } \\
\underline{6-1573677}\end{array}$ & $\begin{array}{l}\text { GGGGAUGUUAUUGGCUUCGACGCCGGUGAUGAAACUCAUAGAUGCAUGCCGAGAGCGCAUUUU } \\
\text { CUCUCGUAAAUAAAAUUUGCAUUUAAAUAGUCGCACGUGACCACAUGGUCCUUCAUGAGUACG } \\
\text { UAAAUGCUGCUGGGAUUACAUAAUAACCUAAUCCUAGCGUCCGCUUCCUAGAAUACUUGUGGU } \\
\text { CUGGGAACCCGACUGAAGCGCACGCACACAAGUCCGUAUAGAGUCAAGCCUCGGGGCUUUAUA } \\
\text { CCAAACUUAGAGGAUCGCACUUUGUACCCUGUUCGUCGGGUCACUUGGUGUUAAAACAAUAGA } \\
\text { CGAUAUCUAAGCAUGUAGUAUUCUCGAGCGUAGUGCUGGCGGACGCGGGUUCAACUCCCGCCA } \\
\text { UCUCCACCA }\end{array}$ \\
\hline $\begin{array}{l}\text { P. aeruginosa } \\
\text { NC 002516.2/901872- } \\
\underline{901520}\end{array}$ & $\begin{array}{l}\text { GGGGCCGAUUAGGAUUCGACGCCGGUAACAAAACUUGAGGGGCAUGCCGAGCUGGUAGCAGAA } \\
\text { CUCGUAAAUUCGCUGCUGCAAACUUAUAGUUGCACGUGACCACAUGGUCCUUCAUGAGUACGU } \\
\text { AAAUGCUGCUGGGAUUACAUAAUAACCUAAUCCUAGCCAGUCGCUAGGGGAUGCCUGUAAACC } \\
\text { CGAAACGACUGUCAGAUAGAACAGGAUCGCCGCCAAGUUCGCUGUAGACGUAACGGCUAAAAC } \\
\text { UCAUACAGCUCGCUCCAAGCACCCUGCCACUCGGGCGGCGCGGAGUUAACUCAGUAGAGCUGG } \\
\text { CUAAGCAUGUAGAACCGAUAGCGGAGAGCUGGCGGACGGGGGUUCAAAUCCCCCCGGCUCCAC } \\
\text { CA }\end{array}$ \\
\hline $\begin{array}{l}\text { E. cloacae } \\
\text { NC 016514.1/3580054- } \\
\underline{3580417}\end{array}$ & $\begin{array}{l}\text { GGGGCUGAUUCUGGAUUCGACGGGAUUUGCGAAACCCAAGGUGCAUGCCGAGGGGCGGUUUGC } \\
\text { CUCGUAAAAAGCCGCAAAAAAAUAGUCGCACGUGACCACAUGGUCCUUCAUGAGUACGUAAAU } \\
\text { GCUGCUGGGAUUACAUAAUAACCUAAUCCUAGCCCUCUCUCCCUAGCUUCCGCUCUUAAGACG } \\
\text { GGGAUUCAAGAGAGGUCAAACCCAAAAGAGAUCGCGUGGAAGCCCUGCCUGGGGUUGAAGCGU } \\
\text { UAAAACUAAUCAGGCUAGUACGUUAGUGGCGUGUUUGUUCGCAGCUGGCGUGCGAAUGUAAAG } \\
\text { ACAAACUAAGCAUGUAGUACCGAGGAUGUAGAAAUUUCGGACGCGGGUUCAACUCCCGCCAGC } \\
\text { UCCACCA }\end{array}$ \\
\hline \multirow[t]{2}{*}{$\begin{array}{l}\text { E. coli } \\
\text { (Guyomar et al ; 2020) } \\
\text { NC 000913.2/2753615- } \\
\underline{2753977}\end{array}$} & $\begin{array}{l}\text { GGGGCUGAUUCUGGAUUCGACGGGAUUUGCGAAACCCAAGGUGCAUGCCGAGGGGCGGUUGGC } \\
\text { CUCGUAAAAAGCCGCAAAAAAUAGUCGCACGUGACCACAUGGUCCUUCAUGAGUACGUAAAUG } \\
\text { CUGCUGGGAUUACAUAAUAACCUAAUCCUAGCCCUCUCUCCCUAGCCUCCGCUCUUAGGACGG } \\
\text { GGAUCAAGAGAGGUCAAACCCAAAAGAGAUCGCGUGGAAGCCCUGCCUGGGGUUGAAGCGUUA } \\
\text { AAACUUAAUCAGGCUAGUUUGUUAGUGGCGUGUCCGUCCGCAGCUGGCAAGCGAAUGUAAAGA } \\
\text { CUGACUAAGCAUGUAGUACCGAGGAUGUAGGAAUUUCGGACGCGGGUUCAACUCCCGCCAGCU } \\
\text { CCACCA }\end{array}$ \\
\hline & tmRNA $A_{G F P 11} V 2$ sequence \\
\hline P. aeruginosa & $\begin{array}{l}\text { GGGGCCGAUUAGGAUUCGACGCCGGUAACAAAACUUGAGGGGCAUGCCGAGCUGGUAGCAGAA } \\
\text { CUCGUAAAUUCGCUGCUGCAAACUUAUAGUUGCACGUGACCACAUGGUCCUUCAUGAGUACGU } \\
\text { AAAUGCUGCUGGGAUUACAUAACUAGCUGCUUAAUGCGGCUAGCAGUCGCUAGGGGAUGCCUG } \\
\text { UAAACCCGAAACGACUGUCAGAUAGAACAGGAUCGCCGCCAAGUUCGCUGUAGACGUAACGGC } \\
\text { UAAAACUCAUACAGCUCGCUCCAAGCACCCUGCCACUCGGGCGGCGCGGAGUUAACUCAGUAG } \\
\text { AGCUGGCUAAGCAUGUAGAACCGAUAGCGGAGAGCUGGCGGACGGGGGUUCAAAUCCCCCCGG } \\
\text { CUCCACCA }\end{array}$ \\
\hline
\end{tabular}


bioRxiv preprint doi: https://doi.org/10.1101/2020.12.16.423090; this version posted December 17,2020 . The copyright holder for this preprint (which was not certified by peer review) is the author/funder. All rights reserved. No reuse allowed without permission.

JBC "Methods and Resources" submission. Thépaut et al., Evaluation of trans-translation in ESKAPE bacteria

526 Supplementary Table 2: E. coli and ESKAPE SmpB amino acid sequences

\begin{tabular}{|c|c|c|}
\hline Species & Accession numbers & SmpB sequence \\
\hline E. faecium & $\begin{array}{l}\text { NC_017960.1/200271 } \\
\text { 9-2002255 }\end{array}$ & $\begin{array}{l}\text { MPKGEGKLIAQNKKARHDYS I I DTMEAGMVLQGTEIKSIR } \\
\text { NSRINLKDGFIRVRNGEAFLHNVH I SPYEQGNIFNHDPLR } \\
\text { TRKLLLHKKQI IRLENELKNTGITVVPLKVYIRNGYAKVL } \\
\text { IGLAKGKKSYDKREDLKRKDIDRQIDRTLKNFSR }\end{array}$ \\
\hline S. aureus & $\begin{array}{l}\text { NZ GG7744880.1/1107 } \\
\underline{769-1107305}\end{array}$ & $\begin{array}{l}\text { MAKKKSPGTLAENRKARHDYNIEDTIEAGIVLQGTEIKS I } \\
\text { RRGSANLKDSYAQVKNGEMYLNNMHIAPYEEGNRFNHDPL } \\
\text { RSRKLLLHKREI IKLGDQTRE IGYS IVPLKLYLKHGHCKV } \\
\text { LLGVARGKKKYDKRQALKEKAVKRDVARDMKARY }\end{array}$ \\
\hline K. pneumoniae & $\begin{array}{l}\text { NC } 017540.1 / 374280 \\
7-3743289\end{array}$ & $\begin{array}{l}\text { MTKKKAHKPGSATIALNKRARHEYFIEDEYEAGLALQGWE } \\
\text { VKSLRAGKANIGDSYVILKDGEAFLFGANFTPMAVASTHY } \\
\text { VCDPTRTRKLLLNQRELDTLYGRINREGYTVVALSLYWKN } \\
\text { AWCKVKIGVAKGKKQHDKRTDLKDREWALDKARIMKHAGR }\end{array}$ \\
\hline A. baumannii & $\frac{\text { NZ KB849843.1/1 }}{643614-1644090}$ & $\begin{array}{l}\text { MAKATVVKKHNGGTIAQNKRARHDYFIEEKFEAGMSLLGW } \\
\text { EVKSLRAGRMSLTESYVIFKNGEAFLFGAQIQPLLSASTH } \\
\text { IVPEATRTRKLLLSRRELEKLMGAVNQKGYSCVPLACYWK } \\
\text { GHLVKLEIALVKGKQLHDKRATEKERDWQRDKARIFHK }\end{array}$ \\
\hline P. aeruginosa & $\frac{\text { NC } 002516.2 / 535}{3783-5354262}$ & $\begin{array}{l}\text { MAKQKKHPSGTIAQNKKALHDYFIEQRFEAGVALAGWEVK } \\
\text { SLRAGKAQLVDSYVLLKDGEAWLLGSHITPLTTASTHVIA } \\
\text { DPVRTRKLLLHKRELGKLFGAVQQKGYACVALSMYWKKHL } \\
\text { VKCEIALAKGKKDFDKRHTEKERDSDREIQRAMRHGKDD }\end{array}$ \\
\hline E. cloacae & $\begin{array}{l}\text { NC } 016514.1 / 357 \\
9482-3579964 \\
\end{array}$ & $\begin{array}{l}\text { MTKKKAHKPGSATIALNKRARHEYFIEEEFEAGLALQGWE } \\
\text { VKSLRAGKANIGDSYVI LKDGEAFLFGANFTPLTVASSHY } \\
\text { VCDPTRTRKLLLNKRELESLYGRINREGFTVVALSLYWKN } \\
\text { AWCKVKVGVAKGKKQHDKRTDLKEREWQLDKARIMKNAGR }\end{array}$ \\
\hline E. coli & $\begin{array}{l}\text { NC } 000913.2 / 275291 \\
8-2753400\end{array}$ & $\begin{array}{l}\text { MTKKKAHKPGSATIALNKRARHEYFIEEEFEAGLALQGWE } \\
\text { VKSLRAGKANISDSYVLLRDGEAFLFGANITPMAVASTHV } \\
\text { VCDPTRTRKLLLNQRELDSLYGRVNREGYTVVALSLYWKN } \\
\text { AWCKVKIGVAKGKKQHDKRSDIKEREWQVDKARIMKNAHR }\end{array}$ \\
\hline
\end{tabular}

527 
bioRxiv preprint doi: https://doi.org/10.1101/2020.12.16.423090; this version posted December 17, 2020. The copyright holder for this preprint (which was not certified by peer review) is the author/funder. All rights reserved. No reuse allowed without permission.

JBC "Methods and Resources" submission. Thépaut et al., Evaluation of trans-translation in ESKAPE bacteria

529 Supplementary Table 3: Primers and antisense oligonucleotide sequences.

\begin{tabular}{|c|c|c|c|c|}
\hline & Name & $\begin{array}{l}\text { Letter/ } \\
\text { Number }\end{array}$ & Sequence & Reference \\
\hline \multirow{3}{*}{ Primers } & GFPfold_for & $\# 1$ & $5^{\prime}$ CTCGATCCCGCGAAATTAATACG $\mathbf{3}^{\prime}$ & \multirow{4}{*}{$\begin{array}{l}\text { Guyomar } \\
\text { et al., } 2020\end{array}$} \\
\hline & GFP1-10nonSTOP_rev & $\# 2$ & $\begin{array}{l}5^{\prime} \text { стTTTCGTTGGGATCTTTCG } \mathbf{3}^{\prime} \\
5^{\prime}\end{array}$ & \\
\hline & alaGFPfold_rev & \#3 & $\begin{array}{l}\text { CCGGCCTAGGTTATGTAATCCCAGCAGCATTT } \\
\text { ACGTACTCATGAAGGACCATGTGGTCACGTGC } \\
\text { CTTTTCGTTGGGATCTTTCGAAAG } \mathbf{3}^{\prime}\end{array}$ & \\
\hline $\begin{array}{c}\text { Antisense } \\
\text { oligonucleotide }\end{array}$ & Antisense tmRNA & A & 5' GCTGCTAAAGCGTAGTTTTCGTCGTT 3' & \\
\hline
\end{tabular}

531 Supplementary Table 4: PCR product sequences for in vitro trans-translation. The T7 promoter is 532 underlined, the RBS sequence is green, the start and stop codons are red, and the tmRNA alanine resume 533 codon is orange.

\begin{tabular}{|c|c|c|}
\hline Name & Sequence & $\begin{array}{c}\text { Reference } \\
.\end{array}$ \\
\hline sfGFP1-10 & $\begin{array}{l}\text { 5'CTCGATCCCGCGAAATAATACGACTCACTATAGGGGAATTGTGAGCGGATAACAATT } \\
\text { CCCCTCTAGAAATAATTTGTTAACTTTAAGAAGGAGATATACATATGGGTGGCACTAG } \\
\text { TAGCAAAGGAGAAGAACTTTTCACTGGAGTTGTCCCAATTCTTGTTGAATTAGATGGTGA } \\
\text { TGTTAATGGGCACAAATTTTCTGTCAGAGGAGAGGGTGAAGGTGATGCTACAATCGGAAA } \\
\text { ACTCACCCTTAAATTATTTGCACTACTGGAAAATACCTGTTCCATGGCCAACACTTGT } \\
\text { CACTACTCTGACCTATGGTGTTCAATGCTTTTCCCGTTATCCGGATCACATGAAAAGGCA } \\
\text { TGACTTTTTCAAGAGTGCCATGCCCGAAGGTTATGTACAGGAACGCACTATATCTTTCAA } \\
\text { AGATGACGGGAAATACAAGACGCGTGCTGTAGTCAAGTTTGAAGGTGATACCCTTGTTAA } \\
\text { TCGTATCGAGTAAAGGGTACTGATTTTAAAGAAGATGGAAACATTCTCGGACACAAACT } \\
\text { CGAGTACAACTTTAACTCACACAATGTATACATCACGGCAGACAAACAAAAGAATGGAAT } \\
\text { CAAAGCTAACTTCACAGTTCGCCACAACGTTGAAGATGGTTCCGTTCAACTAGCAGACCA } \\
\text { TTATCAACAAAATACTCCAATTGGCGATGGCCCTGTCCTTTTACCAGACAACCATTACCT } \\
\text { GTCGACACAAACTGTCCTTTCGAAAGATCCCAACGAAAAG3' }\end{array}$ & $\begin{array}{l}\text { Guyomar } \\
\text { et al., } 2020\end{array}$ \\
\hline sfalaGFP & $\begin{array}{l}\text { 5'CTCGATCCCGCGAAATTAATACGACTCACTATAGGGGAATTGTGAGCGGATAACAATT } \\
\text { CCCCTCTAGAAATAATTTGTTTAACTTTAAGAAGAGATATACATATGGGTGGCACTAG } \\
\text { TAGCAAAGGAGAAGAACTTTTCACTGGAGTTGTCCCAATTCTTGTTGAATTAGATGGTGA } \\
\text { TGTTAATGGGCACAAATTTCTGTCAGAGGAGAGGGTGAAGGTGATGCTACAATCGGAAA } \\
\text { ACTCACCCTTAAATTATTTGCACTACTGGAAAACTACTGTTCCATGGCCAACACTTGT } \\
\text { CACTACTCTGACCTATGGTGTTCAATGCTTTTCCCGTTATCCGGATCACATGAAAAGGCA } \\
\text { TGACTTTTTCAAGAGTGCCATGCCCGAAGGTTATGTACAGGAACGCACTATATCTTTCAA } \\
\text { AGATGACGGGAAATACAAGACGCGTGCTGTAGTCAAGTTTGAAGGTGATACCCTTGTTAA } \\
\text { TCGTATCGAGTTAAAGGGTACTGATTTTAAAGAAGATGGAAACATTCTCGGACACAAACT } \\
\text { CGAGTACAACTTTAACTCACACAATGTATACATCACGGCAGACAAACAAAAGAATGGAAT } \\
\text { CAAAGCTAACTTCACAGTTCGCCACAACGTTGAAGATGGTTCCGTTCAACTAGCAGACCA } \\
\text { TTATCAACAAAATACTCCAATTGGCGATGGCCCTGTCCTTTTACCAGACAACCATTACCT } \\
\text { GTCGACACAAACTGTCCTTTCGAAAGATCCCAACGAAAAGGCACGTGACCACATGGTCCT } \\
\text { TCATGAGTACGTAAATGCTGCTGGGATTACATAACCTAGGCCGG3' }\end{array}$ & $\begin{array}{l}\text { Guyomar } \\
\text { et al., } 2020\end{array}$ \\
\hline
\end{tabular}


bioRxiv preprint doi: https://doi.org/10.1101/2020.12.16.423090; this version posted December 17, 2020. The copyright holder for this preprint (which was not certified by peer review) is the author/funder. All rights reserved. No reuse allowed without permission.

JBC “Methods and Resources" submission. Thépaut et al., Evaluation of trans-translation in ESKAPE bacteria

Supplementary Table 5: Plasmid list. These synthesized sequences were cloned by GenScript in pUC19 between the HindIII and BamHI restriction sites or in pET22b+ between the NdeI and Xhol restriction sites. The $\mathrm{T} 7$ promoter is grey and underlined, the eleventh domain is light green, and the mutations making up for the formation of the $\mathrm{H} 5$ helix are dark green. BsmB1 or EarI allow generation of the 3 'end of tmRNA. SmpB sequences are codon optimized for $E$. coli.

\begin{tabular}{|c|c|c|}
\hline & pUC19E.faeciumtmRNA GFP11 & $\begin{array}{l}\text { aagctTAATACGACTCACTATAGGGGACGTTACGGATTCGACAGGCACAGTCGAG } \\
\text { CTTGAATTCGTTTCGTAGGTTACGTCTACGTAAAAACGTTACAGTTAAATATAA } \\
\text { CTGCACGTGACCACATGGTCCTTCATGAGTACGTAAATGCTGCTGGGATTACATA } \\
\text { ATAACCTAATCCTAGCGATCCTCTCGGCATCGCCCATGTGCTCGAGTAAGGGTCC } \\
\text { TAACTTTAGTGGGATACGTTTCAACTTTCCGTCTGTAAGTTGAAAAAGAGAACAT } \\
\text { CAGACTAGCGATACAGAATGCCTGTCACTCGGCAAGCTGTAAAGTGAATCCTTAA } \\
\text { ATGAGTTGACTATGAACGTAGATTTTTAAGTGGCGATGTGTTTGGACGCGGGTTC } \\
\text { GACTCCCGCCGTCTCCACCaCGAAGAGgatCC }\end{array}$ \\
\hline & pUC19S.aureustmRNA ${ }_{\text {GFP11 }}$ & $\begin{array}{l}\text { aagctTAATACGACTCACTATAGGGGACGTTCATGGATTCGACAGGGGTCCCCCG } \\
\text { AGCTCATTAAGCGTGTCGGAGGGTTGTCTTCGTCATCAACACACACAGTTTATAA } \\
\text { TAACTGCACGTGACCACATGGTCCTTCATGAGTACGTAAATGCTGCTGGGATTAC } \\
\text { ATAATAACCTAATCCTAGCATCGCCTAACAGCATTTCCTATATGCTGTTAACGCG } \\
\text { ATTCAACCTTAATAGGATATGCTAAACACTGCCGTTGAAGTCTGTTTAGAAGAA } \\
\text { ACTTAATCAAGCTAGCATCATGTTGGTTGTTTATCACTTTTCATGATGCGAAACC } \\
\text { TTTCGATAAACTACACACGTAGAAAGATGTGTATCAGGACCTCTGGACGCGGGTT } \\
\text { CAAATCCCGCCTCTCCACCatCGAAGAGgatCC }\end{array}$ \\
\hline 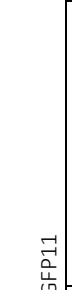 & pUC19K.pneumoniaetmRNA & $\begin{array}{l}\text { aagctTAATACGACTCACTATAGGGGCTGATTCTGGATTCGACGGGATTTGCGAA } \\
\text { ACCCAAGGTGCATGCCGAGGGGCGGTTGGCCTCGTAAAAAGCCGCAAAAAATAGT } \\
\text { CGCACGTGACCACATGGTCCTTCATGAGTACGTAAATGCTGCTGGGATTACATAA } \\
\text { TAACCTAATCCTAGCCCTCTCTCCCTAGCTTCCGCTCTTAAGACGGGGATCAAAG } \\
\text { AGAGGTCAAACCCAAAAGAGATCGCGTGGATGCCCTGCCTGGGGTTGAAGCGTTA } \\
\text { AATCTCATCAGGCTAGTTGTTAGTGGCGTGTCTGTCGCAGCTGGCAAGCGAAT } \\
\text { GTAAAGACTGACTAAGCATGTAGTGCCGAGGATGTAGGAATTTCGGACGCGGGTT } \\
\text { CAACTCCCGCCAGCTCCACCaGGAGACGgatCC }\end{array}$ \\
\hline 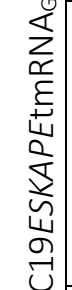 & pUC19A.baumanniitmRNA $A_{G F P 11}$ & $\begin{array}{l}\text { aagctTAATACGACTCACTATAGGGGATGTTATTGGCTTCGACGCCGGTGATGAA } \\
\text { ACTCATAGATGCATGCCGAGAGCGCATTTTCTCTCGTAAATAAAATTTGCATTTA } \\
\text { AATAGTCGCACGTACCACATGGTCCTTCATGAGTACGTAAATGCTGCTGGATT } \\
\text { ACATAATAACCTAATCCTAGCGTCCGCTTCCTAGAATACTTGTGGTCTGGGAACC } \\
\text { CGACTGAAGCGCACGCACACAAGTCCGTATAGAGTCAAGCCTCGGGGCTTTATAC } \\
\text { CAAACTTAGAGGATCGCACTTTGTACCCTGTTCGTCGGGTCACTTGGTGTTAAAA } \\
\text { CAATAGACGATATCTAAGCATGTAGTATTCTCGAGCGTAGTGCTGGCGGACGCGG } \\
\text { GTTCAACTCCCGCCATCTCCACCaGGAGACGgatCC }\end{array}$ \\
\hline 그 & pUC19P.aeruginosatmRNA $A_{G F P 11}$ & $\begin{array}{l}\text { aagctTAATACGACTCACTATAGGGGCCGATTAGGATTCGACGCCGGTAACAAAA } \\
\text { CTTGAGGGGCATGCCGAGCTGGTAGCAGAACTCGTAAATTCGCTGCTGCAAACTT } \\
\text { ATAGTTGCACGTGACCACATGGTCCTTCATGAGTACGTAAATGCTGCTGGGATTA } \\
\text { CATAATAACCTAATCCTAGCCAGTCGCTAGGGGATGCCTGTAAACCCGAAACGAC } \\
\text { TGTCAGATAGAACAGGATCGCCGCCAAGTTCGCTGTAGACGTAACGGCTAAAACT } \\
\text { CATACAGCTCGCTCCAAGCACCCTGCCACTCGGGCGGCGCGGAGTTAACTCAGTA } \\
\text { GAGCTGGCTAAGCATGTAGAACCGATAGCGGAGAGCTGGCGGACGGGGGTTCAAA } \\
\text { TCCCCCCGGCTCCACCAGGAGACGgatCC }\end{array}$ \\
\hline & pUC19E.cloacaetmRNA ${ }_{G F P 11}$ & $\begin{array}{l}\text { aagctTAATACGACTCACTATAGGGGCTGATTCTGGATTCGACGGGATTTGCGAA } \\
\text { ACCCAAGGTGCATGCCGAGGGGCGGTTTGCCTCGTAAAAAGCCGCAAAAAAATAG } \\
\text { TCGCACGTGACCACATGGTCCTTCATGAGTACGAAATGCTGCTGGGATACATA } \\
\text { ATAACCTAATCCTAGCCCTCTCTCCCTAGCTTCCGCTCTTAAGACGGGGATTCAA } \\
\text { GAGAGGTCAAACCCAAAAGAGATCGCGTGGAAGCCCTGCCTGGGGTTGAAGCGTT } \\
\text { AAAACTAATCAGGCTAGTACGTTAGTGGCGTGTTTGTTCGCAGCTGGCGTGCGAA } \\
\text { TGTAAAGACAAACTAAGCATGTAGTACCGAGGATGTAGAAATTTCGGACGCGGGT } \\
\text { TCAACTCCCGCCAGCTCCACCaGGAGACGgatCC }\end{array}$ \\
\hline & pUC19P.aeruginosatmRNA $A_{G F P 11} V 2$ & $\begin{array}{l}\text { aagctTAATACGACTCACTATAGGGGCCGATTAGGATTCGACGCCGGTAACAAAA } \\
\text { CTTGAGGGGCATGCCGAGCTGGTAGCAGAACTCGTAAATTCGCTGCTGCAAACTT } \\
\text { ATAGTTGCACGTGACCACATGGTCCTCATGAGTACGTAAATGCTGCTGGGATTA } \\
\text { CATAACtagCtgcttaa TGCGGCTAGCAGTCGCTAGGGGATGCCTGTAAACCCGA } \\
\text { AACGACTGTCAGATAGAACAGGATCGCCGCCAAGTCGCTGTAGACGTAACGGCT } \\
\text { AAAACTCATACAGCTCGCTCCAAGCACCCTGCCACTCGGGCGGCGCGGAGTTAAC } \\
\text { TCAGTAGAGCTGGCTAAGCATGTAGAACCGATAGCGGAGAGCTGGCGGACGGGGG } \\
\text { TTCAAATCCCCCCGCTCCACCAGGAGACGgatCC }\end{array}$ \\
\hline
\end{tabular}


bioRxiv preprint doi: https://doi.org/10.1101/2020.12.16.423090; this version posted December 17, 2020. The copyright holder for this preprint (which was not certified by peer review) is the author/funder. All rights reserved. No reuse allowed without permission.

JBC “Methods and Resources" submission. Thépaut et al., Evaluation of trans-translation in ESKAPE bacteria

\begin{tabular}{|c|c|c|}
\hline & pET22b+E.faeciumSmpB & $\begin{array}{l}\text { CATATGCCGAAGGGCGAGGGCAAACTGATTGCGCAGAACAAGAAAGCGCGTCACG } \\
\text { ACTACAGCATCATTGATACCATGGAGGCGGGTATGGTGCTGCAAGGCACCGAAAT } \\
\text { CAAAAGCATTCGTAACAGCCGTATCAACCTGAAGGACGGTTCATTCGTGTGCGT } \\
\text { AACGGCGAGGCGTTTCTGCACAACGTTCACATCAGCCCGTATGAACAGGGTAACA } \\
\text { TTTTCAACCACGATCCGCTGCGTACCCGTAAACTGCTGCTGCACAAGAAACAAAT } \\
\text { CATTCGTCTGGAGAACGACTGAAAACACCGGTATCACCGTGGTTCCGCTGAAG } \\
\text { GTGTACATTCGTAACGGCTATGCGAAGGTTCTGATCGGTCTGGCGAAAGGCAAGA } \\
\text { AAAGCTACGACAAGCGTGAAGATCTGAAGCGTAAAGACATCGATCGTCAGATTGA } \\
\text { CCGTACCCTGAAGAACTTTAGCCGTCTCGAG }\end{array}$ \\
\hline & pET22b+S.aureusSmpB & $\begin{array}{l}\text { CATATGGCGAAGAAAAAGAGCCCGGGTACCCTGGCGGAGAACCGTAAAGCGCGTC } \\
\text { ACGACTATAACATCGAGGATACCATTGAAGCGGGTATCGTGCTGCAGGGCACCGA } \\
\text { GATCAAGAGCATTCGTCGTGGTAGCGCGAACCTGAAAGACAGCTACGCGCAAGTT } \\
\text { AAGAACGGCGAAATGTATCTGAACAACATGCACATTGCGCCGTACGAGGAAGGTA } \\
\text { ACCGTTTCAACCACGACCCGCTGCGTAGCCGTAAGCTGCTGCTGCACAAACGTGA } \\
\text { GATCATTAAGCTGGGTGATCAGACCCGTGAAATTGGCTACAGCATCGTGCCGCTG } \\
\text { AAGCTGTATCTGAAACACGGCCACTGCAAAGTGCTGCTGGGTGTTGCGCGTGGCA } \\
\text { AAAAGAAATATGATAAGCGTCAAGCGCTGAAGGAAAAAGGGTGAAACGTGACGT } \\
\text { TGCGCGTGATATGAAGGCGCGTTACCTCGAG }\end{array}$ \\
\hline 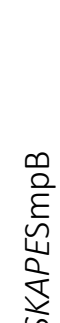 & pET22b+K.pneumoniaeSmpB & $\begin{array}{l}\text { CATATGACCAAGAAAAAGGCGCACAAACCGGGTAGCGCGACCATCGCGCTGAACA } \\
\text { AGCGTGCGCGTCACGAATACTTCATTGAGGACGAATATGAGGCGGGTCTGGCGCT } \\
\text { GCAGGGTTGGGAAGTGAAAAGCCTGCGTGCGGGCAAGGCGAACATCGGCGACAGC } \\
\text { TATGTTATTCTGAAAGATGGTGAAGCGTTCCTGTTTGGCGCGAACTTTACCCCGA } \\
\text { TGGCGGTGGCGAGCACCCACTACGTTTGCGACCCGACCCGTACCCGTAAGCTGCT } \\
\text { GCTGAACCAGCGTGAACTGGATACCCTGTACGGTCGTATCAACCGTGAGGGCTAT } \\
\text { ACCGTGGTTGCGCTGAGCCTGTACTGGAAAAACGCGTGGTGCAAAGTGAAGATTG } \\
\text { GTGTTGCGAAGGGCAAAAAGCAACACGACAAACGTACCGACCTGAAGGATCGTGA } \\
\text { GTGGGCGCTGGATAAAGCGCGTATCATGAAGCACGCGGGCCGTCTCGAG }\end{array}$ \\
\hline 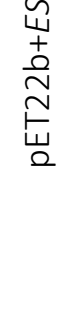 & pET22b+A.baumanniiSmpB & $\begin{array}{l}\text { CATATGGCGAAGGCGACCGTGGTTAAGAAACACAACGGTGGCACCATCGCGCAGA } \\
\text { ACAAGCGTGCGCGTCACGACTACTTCATTGAGGAAAAATTTGAGGCGGGTATGAG } \\
\text { CCTGCTGGGCTGGGAAGTGAAGAGCCTGCTGCGGGTCGTATGAGCCTGACCGAG } \\
\text { AGCTATGTTATCTTCAAAAACGGTGAAGCGTTCCTGTTTGGTGCGCAGATCCAAC } \\
\text { CGCTGCTGAGCGCGAGCACCCACATTGTGCCGGAGGCGACCCGTACCCGTAAACT } \\
\text { GCTGCTGAGCCGTCGTGAGCTGGAAAAGCTGATGGGTGCGGTGAACCAAAAAGGC } \\
\text { TACAGCTGCGTTCCGCTGGCGTGCTATTGGAAGGGTCACCTGGTGAAACTGGAAA } \\
\text { TCGCGCTGGTTAAGGGCAAACAGCTGCACGATAAGCGTGCGACCGAGAAAGAACG } \\
\text { TGACTGGCAACGTGATAAGGCGCGTATTTTTCACAAACTCGAG }\end{array}$ \\
\hline & pET22b+P.aeruginosaSmpB & $\begin{array}{l}\text { CATATGGCGAAACAGAAGAAACACCCGAGCGGTACCATCGCGCAAAACAAGAAAG } \\
\text { CGCTGCACGACTACTTCATTGAGCAGCGTTTTGAAGCGGGTGTGGCGCTGGCGGG } \\
\text { TTGGGAAGTGAAAAGCCTGCGTGCGGGCAAGGCGCAACTGGTGGACAGCTATGTT } \\
\text { CTGCTGAAAGATGGTGAAGCGTGGCTGCTGGGTAGCCACATTACCCCGCTGACCA } \\
\text { CCGCGAGCACCCACGTGATTGCGGATCCGGTTCGTACCCGTAAGCTGCTGCTGCA } \\
\text { CAAACGTGAGCTGGGCAAGCTGTTCGGCGCGGTGCAGCAAAAGGGTTACGCGTGC } \\
\text { GTTGCGCTGAGCATGTATTGGAAGAAACACCTGGTGAAATGCGAGATCGCGCTGG } \\
\text { CGAAGGGCAAGAAAGACTTTGATAAACGTCACACCGAGAAGGAACGTGACAGCGA } \\
\text { TCGTGAAATTCAGCGTGCGATGCGTCACGGCAAGGACGATCTCGAG }\end{array}$ \\
\hline & pET22b+E.cloacaeSmpB & $\begin{array}{l}\text { CATATGACCAAGAAAAAGGCGCACAAACCGGGTAGCGCGACCATCGCGCTGAACA } \\
\text { AGCGTGCGCGTCACGAATACTTCATTGAGGAAGAGTTTGAGGCGGGTCTGGCGCT } \\
\text { GCAGGGTTGGGAAGTTAAAAGCCTGCGTGCGGGCAAGGCGAACATCGGCGACAGC } \\
\text { TACGTGATTCTGAAAGATGGCGAGGCGTTCCTGTTTGGCGCGAACTTCACCCCGC } \\
\text { TGACCGTTGCGAGCAGCCACTATGTGTGCGACCCGACCGTACCCGTAAACTGCT } \\
\text { GCTGAACAAGCGTGAACTGGAGAGCCTGTACGGTCGTATCAACCGTGAAGGCTTT } \\
\text { ACCGTGGTTGCGCTGAGCCTGTATTGGAAAAACGCGTGGTGCAAAGTGAAGGTTG } \\
\text { GTGTGGCGAAGGGCAAAAAGCAGCACGACAAACGTACCGATCTGAAGGAGCGTGA } \\
\text { GTGGCAACTGGATAAAGCGCGTATTATGAAGAACGCGGGCCGTCTCGAGCTCGAG }\end{array}$ \\
\hline
\end{tabular}

